\title{
The diagnostic analysis of the planet bearing faults using the torsional vibration signal
}

Song Xue ${ }^{1}$, Ian Howard $^{2} *$, Congsi Wang ${ }^{1}$, Hong Bao ${ }^{1}$, Peiyuan Lian', Gaige Chen ${ }^{1}$, Yan Wang ${ }^{1}$, Yuefei Yan $^{1}$

${ }^{1}$ Key laboratory of Electronic Equipment Structure Design, School of MechanoElectronic Engineering, Xidian University, Xi' an, Shannxi, China

${ }^{2}$ Department of Mechanical Engineering, Curtin University, Bentley, Western Australia, Australia

* Corresponding author. Phone: (+61) 892667047.

E-mai1: i. howard@curtin. edu. au

Abstract: This paper aims to investigate the effectiveness of using the torsional vibration signal as a diagnostic tool for planet bearing fault detection. The inner race of the planet bearing is connected to the planet carrier and its outer race is connected to the planet gear bore hole. When moving, the planet bearing not only spins around the planet gear axis, but also revolves about the sun gear axis. This rotating mechanism poses a challenge for the condition monitoring of the planet bearing because of the variant vibration transfer paths. The transducer mounted on the carrier arm measuring the torsional vibration is theoretically free from this modulation effect and it is used in this research to extract the diagnostic information from the torsional vibration.

A 34 degrees of freedom planetary gear lumped-parameter model with detailed planet bearing model was developed to obtain the dynamic response. The planet bearing was modelled by 5 degrees of freedom, with 2 degrees of freedom from the outer race, 2 degrees of freedom from the inner race and one degree of freedom from the sprung-mass. The variations of the sun-planet and ring-planet mesh stiffnesses were evaluated by the finite element method and the variation of the planet bearing stiffness was evaluated by the Hertzian contact theory. The localized faults on the planet bearing inner race, outer race and the rolling element were created mathematically and then these faults were incorporated into the planetary gear model to obtain the faulted vibration signal.

The linear prediction method and the minimum entropy deconvolution method were 
used to enhance the planet bearing signal and then the amplitude demodulation results were analysed. It was found that the carrier arm instantaneous angular speed was an effective alternative approach for planet gear condition monitoring.

Keyword: Torsional vibration, Planet bearing fault diagnosis, Lumped-parameter model, Amplitude demodulation, Instantaneous angular speed 


\section{Introduction}

Planetary gears, also known as epicyclic gear sets, commonly include several planet gears meshing simultaneously to split the torque and power. With the help of a planet bearing, the planet gear can not only rotate around its own axis, but also around the planetary gear common axis. For the planet bearing, its inner race is usually fixed to the planet pin connecting firmly to the planet carrier, and its outer race is connected firmly to the planet gear bore hole. This configuration also allows the planet bearing to spin around the planet axis with the planet gear, and at the same time to revolve about the sun and ring gear common axis with the planet carrier. However, this rotating mechanism poses a big challenge and remains as one of the most difficult scenarios for planet bearing condition monitoring compared to the bearing condition monitoring in parallel shaft gearing.

The gear faults in the planetary gear have been a research hot spot since 1990s' [1-3]. Numerous researchers have done intensive work in the dynamic modeling of planetary gear vibration to understand the vibration generation mechanisms as well as the dynamic behavior of the transmission in the presence of various types of gear faults and in the signal processing methods to extract the most proper gear fault indicators under different conditions [4-14]. Kahraman and Parker have made significant contributions to the planetary gear dynamic modeling area and their modelling work has become the benchmark to investigate the planetary gear vibration with and without defects in the system [4-8]. From their work, it was found that the sun-planet and ring-planet tooth mesh stiffness variations and the resulting transmission errors were found to be the main internal vibration generation mechanisms for planetary gear systems. Mesh stiffness of the internal gear pair with a crack was then incorporated into the planetary gear model to investigate the dynamic response [9-11]. Some experimental work was carried out to validate the modelling work with the gear defect and it was found that the use of dynamic modelling assists in understanding and identifying the presence 
of the gear defect from the system vibration. The traditional approach for condition monitoring of the planetary gear is using a stationary transducer mounted on the ring gear casing to record all the vibration data when the planet gear passes by, Mark [12]. In the 1990s, a technique was presented for extracting the time/phase domain averages of the tooth meshing vibration of the individual planet gears and of the sun gear in an epicyclic gearbox [1-3]. Based on this, further signal processing techniques which have been used for fixed axis gears could be used here to detect the gear fault. Another important approach for condition monitoring of the planetary gear is using the torsional vibration [13, 14]. It was an advantage to measure the torsional vibration directly to naturally separate the signal from the modulation effect. Zhipeng gave explicit equations for the planetary gear torsional signal model indicating that the only modulation effect in the torsional vibration signal is the amplitude and phase modulation caused by gear faults [13]. Song used the planetary gear dynamic model to investigate the impact of different crack components on the planetary gear torsional signal and it was found that the torsional vibration is an effective alternative approach for the planetary gear condition monitoring [14].

On the other hand, over the past decades, extensive research work has been carried out in the dynamic behavior of the rolling bearing system with and without the presence of bearing defects [15-22] and in the signal processing methods to extract the bearing fault features [23-26]. Hongrui gave a comprehensive review on rolling element bearing modelling methodology and they classified the bearing models into five groups, among which the lumped-parameter model and the dynamic model have been used intensively by the researchers to investigate the rolling element bearing dynamic behavior [15]. One of the most representative bearing dynamic models was proposed by Gupta [16], where the interactions between different components, i.e., the ball-raceway interaction, were all included, and each bearing component has six degrees of freedom. Based on Gupta' s work, researchers have developed various models to investigate the misalignment [17], cage related irregularity [18, 19] and so on [15]. The orbital 
motion of the rolling elements leads to a fluctuation in the stiffness of the bearing and this resultant varying stiffness was found to be the direct internal vibration source for the bearing. For a given bearing operating at a constant shaft speed and load, all of the various forces will be in balance and when a loaded ball encounters a spall, there will be a sudden relaxation of the loading, or, if a ball encounters a high spot or a piece of debris, a sudden increase in loading will occur. The transient forces which are produced will result in rapid accelerations of the bearing components and complex motions can occur including oscillatory contact and impacts between different components. Sarabjeet et al. gave an extensive review of vibration modelling of rolling element bearings with various localized and extended defects [20]. Feng et al. extended Fukata's two degrees of freedom lumped-parameter model by including the effect of slippage of the cage and rolling elements as well as the effect of localized faults in the inner and outer raceway [21]. Later, Sawalhi et al. further developed the work of Feng et al. and a five degree of freedom analytical model was used to simulate the vibration response of a defective ball bearing in a gearbox having localized line spalls [22]. An important feature of their model was including an additional mass-spring-damper system to simulate the typical high-frequency resonant response of a bearing. Signal processing techniques for bearing fault detection and diagnosis by vibration analysis have been used for many years and some earlier techniques were reviewed by Howard in the 1990s [23]. Since then, various new signal processing techniques have been proposed for the bearing fault in different scenarios [24-25], however, envelope analysis still remains as one of the prominent vibration signal processing techniques for detection of the rolling element bearing incipient failure [26]. The fundamental concept of envelope analysis is that each time a localized defect in a rolling element bearing makes contact under load with another surface, an impulse of vibration will be generated, and its energy will be distributed across a very wide frequency range. Therefore, the resonances of the bearing will be excited, and are usually amplitude modulated at the characteristic repetitive defect frequency. Envelope analysis provides 
the mechanism for extracting out the periodic excitation. In the early days, one of the on-going difficulties with envelope analysis was how to determine the best frequency band to envelope and with the development of spectral kurtosis (SK) and the kurtogram, this problem has been largely solved [27]. They provide a means of determining which frequency bands contain the signal of maximum impulsivity. Randall and Antoni gave a tutorial on rolling element bearing diagnosis, where they proposed a diagnostic routine for the bearing fault diagnosis, which included five steps [26].

From the previous literature review, it can be seen that the research for the gear fault diagnosis in the planetary gear as well as the fault diagnosis in the rolling bearing in parallel shaft gear have been well developed and investigated. Whilst, the research for the bearing diagnosis in the planetary gear system has attracted less attention and has been less developed. For the bearings supporting the sun gear and carrier arm, they work in the same way as bearings in the parallel shaft gear, and their fault characteristics and diagnostic methods are similar. For the bearings supporting the planet gears, the planet bearing not only rotates around the planet axis, but also rotates around the sun and ring gear axis. This different rotating mechanism would change the bearing fault characteristics significantly. For the planet bearing dynamic modeling aspect, Jain and Hunt considered the ring gear deformation and a planet bearing defect, developed a dynamics model of a planetary gearbox, and analyzed the spectral characteristic vibration response measured from the ring gear rim [28]. Ali and Alessandro proposed a lumped parameter model with the planet bearing and in their model, the displacement of the inner race was equal to the displacement of the carrier arm and the displacement of the outer race was equal to the displacement of the planet gear [29]. Gui et al. proposed a planet bearing model with two degrees of freedom [30]. For the signal processing aspect, Bonnardot et al. proposed a signal denoising method based on angle domain resampling, to analyze the vibration signal of a planetary gearbox with a faulty planet bearing [31]. Fan and Li experimentally explored the planet bearing diagnostic using an 
internal sensor on the carrier arm and a hybrid approach for planet bearing diagnostics has been proposed [32]. Zhipeng developed the planet bearing vibration signal model for each fault case, considering the modulation effects of load zone variation, time-varying angle between the gear pair meshing and fault induced impact force, as well as the time varying vibration transfer path and then gave the explicit equations for calculating the characteristic frequency of each fault case [33]. Based on the vibration signal model, he further used a joint amplitude and frequency demodulation analysis to reveal the bearing fault [34]. However, there are further requirements for the continuous development of the planet bearing dynamic model to study the interaction between the planet bearing defects and planetary gear system as well as finding new ways to monitor the planet bearing health, especially for critical applications.

This paper aims to investigate the effectiveness of using the torsional vibration signal as a diagnostic tool for the planet bearing defect detection. In section 2, a 34 degree of freedom planetary gear lumped-parameter model is proposed, including detailed modelling of 5 degrees of freedom for each planet bearing. In the following section, the finite element method was used to calculate the gear mesh stiffness and the planet bearing stiffness was estimated based on Hertzian theory. Next, the faults for the inner race, outer race as well as the rolling element, which can be incorporated into the planetary gear dynamic model, were modelled mathematically in section 3. This paper used the carrier arm instantaneous angular speed to discuss the effectiveness of detecting the planet bearing fault and the dynamic responses were obtained in section 4. After enhancing the planet bearing signal, the amplitude demodulation results are presented. Section 5 presents a proposed experimental system that could be developed to provide further verification of the torsional speed fluctuations from the plant bearings faults. The potential advantages and limitations of this method were then discussed in section 6 , followed by the overall conclusions in section 7 . 


\section{The dynamic modelling of a planetary gear system with planet gear bearings}

\section{1 Lumped-parameter mode1}

Mathematical planetary gear models can be used to help understand the complex dynamic response from the gearbox [4-6] and the planetary gear system considered in this study has been developed based on a previous study [14]. The system is a single-stage planetary gear set, which includes an input motor, one sun gear, three planet gears, one ring gear, one carrier arm and an output load, as shown in Fig. 1(a). The difference between the dynamic model used in this study and that used in the previous study is the inclusion of the detailed modeling of the planet bearings. A brief description of the planetary gear system has been shown in Fig. 1(b). In the model, a two dimensional lumped-parameter planetary gear mathematical model was created and each of these gear components has three DOFs: transverse motions in the $\mathrm{x}$-axis and $\mathrm{y}$-axis, and rotation. The transverse motions of the sun, planet, ring and carrier $\left(x_{j}, y_{j}, j=s, r, c, p_{1}, p_{2}, p_{3}\right)$ were simulated with respect to a rotating frame of reference fixed to the carrier.

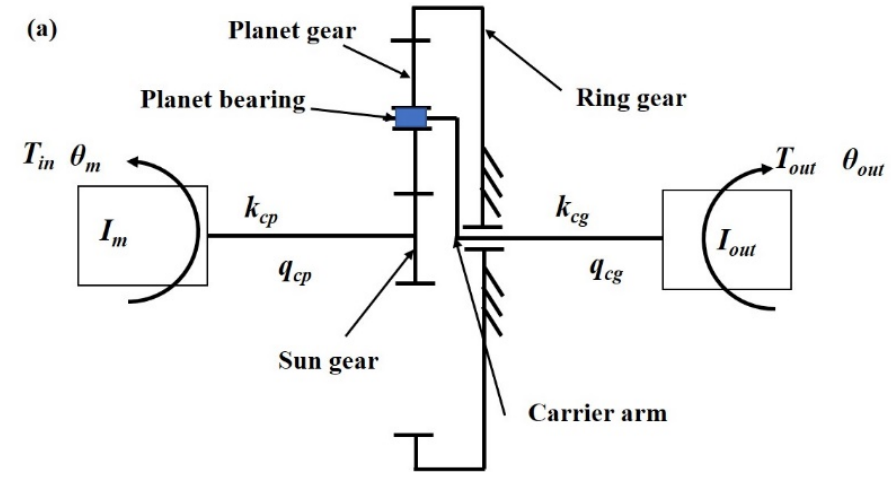




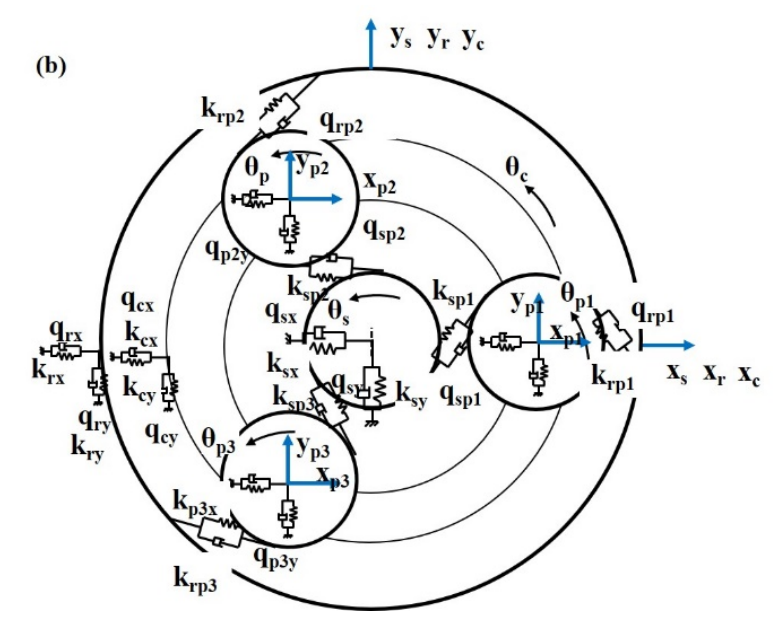

Figure 1 Planetary gear system, (a). the whole transmission train, (b). planetary gear

\section{dynamic model}

The detailed modelling work of the planet bearing has been adopted from the bearing model in [22] and its diagram is shown in Fig. 2. In the arrangement, the inner race is connected to the planet pin, which is clamped on both sides of the carrier arm. The outer race is connected to the bore of the planet gear. In the configuration, the inner race only revolves with the planet carrier while the outer race shares the same kinematic characteristics with the planet gear, which not only revolves around its own axis but also revolves around the sun gear axis. In the model, the planet bearing has five DOFs: inner race transverse motion in the $\mathrm{x}$-axis and $\mathrm{y}$-axis, outer race transverse motion in the $\mathrm{x}$-axis and y-axis and one extra sprung DOF. This extra sprung DOF was used to tune the bearing parameters to represent the high frequency behavior of the bearings and adds a new equation for each bearing but does not alter the structure of the equations of the bearing motion. The transverse motions of the inner race, outer race and sprung system were all simulated with respect to a rotating frame of reference fixed to the carrier. 


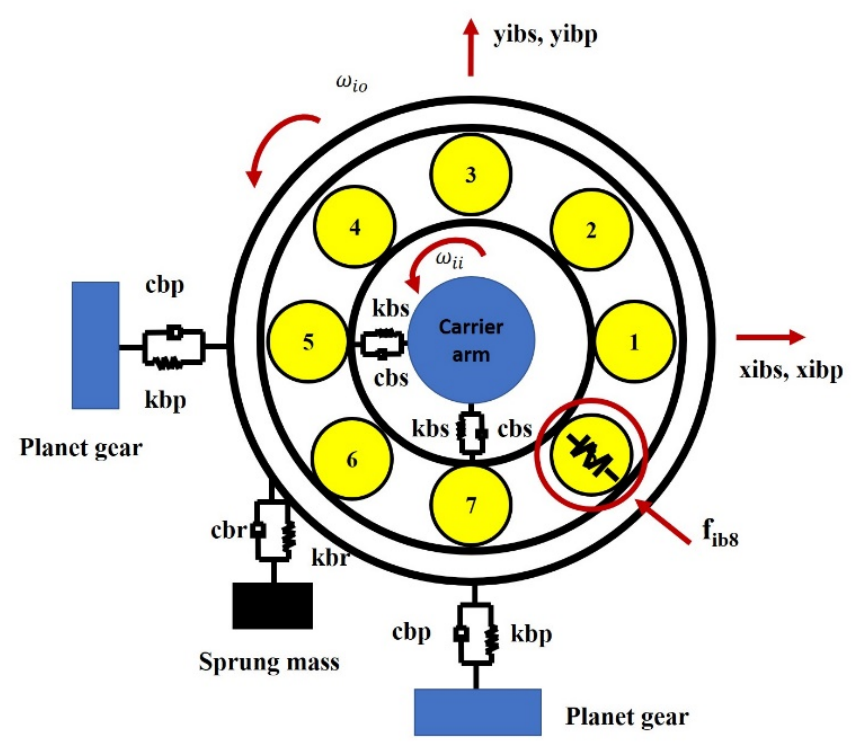

Figure 2 Planet bearing dynamic model

The overall contact deformation, $\delta_{\mathrm{ibj}}$, for the $j$ th rolling element on the $i$ th planet gear bearing can be calculated as follows,

$$
\delta_{\mathrm{ibj}}=\left(\mathrm{x}_{\mathrm{ibs}}-\mathrm{x}_{\mathrm{ibp}}\right) \cos \Phi_{\mathrm{ibj}}+\left(\mathrm{y}_{\mathrm{ibs}}-\mathrm{y}_{\mathrm{ibp}}\right) \sin \Phi_{\mathrm{ibj}}-\mathrm{c}, \quad \mathrm{j}=1, \quad 2, \quad 3, \cdots, \mathrm{n}_{\mathrm{b}},
$$

where $n_{b}$ is the number of rolling elements, $c$ is the radial clearance and $\Phi_{\text {ibj }}$ is the angular position of the rolling elements and it can be calculated as,

$$
\Phi_{\mathrm{ibj}}=\frac{2 \pi(\mathrm{j}-1)}{\mathrm{n}_{\mathrm{b}}}+\omega_{\mathrm{ibc}}^{\mathrm{c}} \mathrm{dt}+\Phi_{\mathrm{ibo}}+\overbrace{(0.5-\text { rand }) \times \Phi_{\text {slip }}}^{\text {slipage }},
$$

where $(0.5-$ rand $) \times \Phi_{\text {slip }}$ defines the slippage between the ball and the race. $\Phi_{\text {ibo }}$ is the initial cage position and $\omega_{\mathrm{ibc}}^{\mathrm{c}}$ is the cage speed measured in the rotating frame. If $\omega_{i b c}$ is the absolute cage speed, it can be calculated by the inner race angular speed, $\omega_{i i}$, and the outer race angular speed, $\omega_{i o}$, as shown in the following,

$$
\omega_{\mathrm{ibc}}=\frac{\omega_{\mathrm{ii}}}{2}\left(1-\frac{\mathrm{D}_{\mathrm{b}}}{\mathrm{D}_{\mathrm{p}}} \cos \alpha\right)+\frac{\omega_{\mathrm{io}}}{2}\left(1+\frac{\mathrm{D}_{\mathrm{b}}}{\mathrm{D}_{\mathrm{p}}} \cos \alpha\right),
$$

where $D_{b}$ is the rolling element diameter, $D_{p}$ is the pitch diameter, and $a$ is the contact angle. Therefore, the cage speed measured in the rotating frame can be calculated as,

$$
\omega_{\mathrm{ibc}}^{\mathrm{c}}=\omega_{\mathrm{ibc}}-\omega_{\mathrm{c}}=\frac{\omega_{\mathrm{ii}}}{2}\left(1-\frac{\mathrm{D}_{\mathrm{b}}}{\mathrm{D}_{\mathrm{p}}} \cos \alpha\right)+\frac{\omega_{\mathrm{io}}}{2}\left(1+\frac{\mathrm{D}_{\mathrm{b}}}{\mathrm{D}_{\mathrm{p}}} \cos \alpha\right)-\omega_{\mathrm{c}} .
$$


Accounting for the fact that compression occurs only for positive values of $\delta_{\mathrm{ibj}}$, contact state $\gamma_{\mathrm{ibj}}$ is introduced as,

$$
\gamma_{\mathrm{ibj}}=\left\{\begin{array}{lr}
1 & \text { if } \boldsymbol{\delta}_{\mathrm{ibj}}>\mathbf{0} \\
0 & \text { otherwise }
\end{array}\right. \text {. }
$$

The ball race contact force $\mathrm{f}_{\mathrm{ibj}}$ due to the $j$ th rolling element on the $i$ th planet is given as,

$$
\mathrm{f}_{\mathrm{ibj}}=\mathrm{k}_{\mathrm{b}} \delta_{\mathrm{ibj}}^{\mathrm{n}} \text {. }
$$

$k_{b}$ is the combined contact stiffness between the rolling element and the races and is calculated in section 2.4. The exponent $n$ was suggested to be 1.5 for ball bearings and 1.1 for roller bearings [22]. Therefore, the summation of the contact forces in the $\mathrm{x}^{-}$and $\mathrm{y}^{-}$- directions for a ball bearing with $\mathrm{n}_{\mathrm{b}}$ balls can be calculated as,

$$
\begin{gathered}
\mathrm{f}_{\mathrm{ibx}}=\mathrm{k}_{\mathrm{b}} \sum_{\mathrm{j}=1}^{\mathrm{n}_{\mathrm{b}}} \gamma_{\mathrm{ibj}} \delta_{\mathrm{ibj}}^{1.5} \cos \Phi_{\mathrm{ibj}}, \\
\mathrm{f}_{\mathrm{iby}}=\mathrm{k}_{\mathrm{b}} \sum_{\mathrm{j}=1}^{\mathrm{n}_{\mathrm{b}}} \gamma_{\mathrm{ibj}} \delta_{\mathrm{ibj}}^{1.5} \sin \Phi_{\mathrm{ibj}} .
\end{gathered}
$$

\section{2 The equations of motion}

The resulting equations of motion for this planetary gear system are shown as follows.

For the rotary motion of the motor, the motion equation is,

$$
\begin{gathered}
\mathrm{I}_{\mathrm{m}} \ddot{\theta}_{\mathrm{m}}=\mathrm{T}_{\mathrm{in}}-\mathrm{T}_{\mathrm{s}}, \\
\mathrm{T}_{\mathrm{s}}=\mathrm{k}_{\mathrm{cp}}\left(\theta_{\mathrm{m}}-\theta_{\mathrm{s}}\right)+\mathrm{q}_{\mathrm{cp}}\left(\dot{\theta}_{\mathrm{m}}-\dot{\theta}_{\mathrm{s}}\right) .
\end{gathered}
$$

For the motion of the sun gear, the differential equation is,

$$
\begin{gathered}
\mathrm{m}_{\mathrm{s}} \ddot{\mathrm{x}}_{\mathrm{s}}+\mathrm{k}_{\mathrm{sx}} \mathrm{x}_{\mathrm{s}}+\mathrm{q}_{\mathrm{sx}} \dot{\mathrm{x}}_{\mathrm{s}}+\sum_{\mathrm{i}=1}^{3}\left[\mathrm{~F}_{\mathrm{spi}} \cos \left(\varphi_{\mathrm{spi}}\right)\right]=\mathrm{m}_{\mathrm{s}} \mathrm{x}_{\mathrm{s}} \Omega^{2}+2 \mathrm{~m}_{\mathrm{s}} \dot{\mathrm{y}}_{\mathrm{s}} \Omega+\mathrm{m}_{\mathrm{s}} \mathrm{y}_{\mathrm{s}} \dot{\Omega}, \\
\mathrm{m}_{\mathrm{s}} \ddot{\mathrm{y}}_{\mathrm{s}}+\mathrm{k}_{\mathrm{sy}} \mathrm{y}_{\mathrm{s}}+\mathrm{q}_{\mathrm{sy}} \dot{\mathrm{y}}_{\mathrm{s}}+\sum_{\mathrm{i}=1}^{3}\left[\mathrm{~F}_{\mathrm{spi}} \sin \left(\varphi_{\mathrm{spi}}\right)\right]=\mathrm{m}_{\mathrm{s}} \mathrm{y}_{\mathrm{s}} \Omega^{2}-2 \mathrm{~m}_{\mathrm{s}} \dot{\mathrm{x}}_{\mathrm{s}} \Omega-\mathrm{m}_{\mathrm{s}} \mathrm{x}_{\mathrm{s}} \dot{\Omega}, \\
\left(\mathrm{I}_{\mathrm{s}} / \mathrm{r}_{\mathrm{s}}\right) \ddot{\theta}_{\mathrm{s}}+\sum_{\mathrm{i}=1}^{3} \mathrm{~F}_{\mathrm{spi}}=\mathrm{T}_{\mathrm{s}} / \mathrm{r}_{\mathrm{s}},
\end{gathered}
$$

where $\mathrm{F}_{\mathrm{spi}}$ is the normal contact force between the sun gear and the ith planet,

$$
\begin{gathered}
\mathrm{F}_{\mathrm{spi}}=\mathrm{k}_{\mathrm{spi}} \delta_{\mathrm{spi}}+\mathrm{q}_{\mathrm{spi}} \dot{\delta}_{\mathrm{spi}}, \\
\delta_{\mathrm{spi}}=\left(\mathrm{x}_{\mathrm{s}}-\mathrm{x}_{\mathrm{pi}}\right) \cos \varphi_{\mathrm{spi}}+\left(\mathrm{y}_{\mathrm{s}}-\mathrm{y}_{\mathrm{pi}}\right) \sin \varphi_{\mathrm{spi}}+\mathrm{r}_{\mathrm{s}} \theta_{\mathrm{s}}+\mathrm{r}_{\mathrm{p}} \theta_{\mathrm{pi}}-\mathrm{r}_{\mathrm{c}} \theta_{\mathrm{c}} \cos \alpha_{\mathrm{sp}},
\end{gathered}
$$




$$
\begin{gathered}
\varphi_{\text {spi }}=\frac{\pi}{2}-\alpha_{\text {sp }}+\varphi_{\mathrm{i}}, \\
\varphi_{\mathrm{i}}=\frac{2 \pi(\mathrm{i}-1)}{3}, \quad \mathrm{i}=1,2,3 .
\end{gathered}
$$

For the motion of the planet gears, the $\mathrm{x}$ and $\mathrm{y}$ components become,

$$
\begin{gathered}
\mathrm{m}_{\mathrm{pi}} \ddot{\mathrm{x}}_{\mathrm{pi}}-\mathrm{k}_{b p}\left(\mathrm{x}_{b p}-\mathrm{x}_{p}\right)-\mathrm{c}_{b p}\left(\dot{\mathrm{x}}_{b p}-\dot{\mathrm{x}}_{p}\right)+\mathrm{F}_{\mathrm{spi}} \cos \varphi_{\mathrm{spi}}+\mathrm{F}_{\mathrm{rpi}} \cos \varphi_{\mathrm{rpi}} \\
=\mathrm{m}_{\mathrm{pi}} \mathrm{x}_{\mathrm{pi}} \Omega^{2}+2 \mathrm{~m}_{\mathrm{pi}} \dot{\mathrm{y}}_{\mathrm{pi}} \Omega+\mathrm{m}_{\mathrm{pi}} \mathrm{y}_{\mathrm{pi}} \dot{\Omega}+\mathrm{m}_{\mathrm{pi}} \mathrm{r}_{\mathrm{c}} \Omega^{2} \cos \varphi_{\mathrm{i}} \\
\mathrm{m}_{\mathrm{pi}} \ddot{\mathrm{y}}_{\mathrm{pi}}-\mathrm{k}_{b p}\left(\mathrm{y}_{b p}-\mathrm{y}_{p}\right)-\mathrm{c}_{b p}\left(\dot{\mathrm{y}}_{b p}-\dot{\mathrm{y}}_{p}\right)-\mathrm{F}_{\mathrm{spi}} \sin \varphi_{\mathrm{spi}}-\mathrm{F}_{\mathrm{rpi}} \sin \varphi_{\mathrm{rpi}} \\
=\mathrm{m}_{\mathrm{pi}} \mathrm{y}_{\mathrm{pi}} \Omega^{2}-2 \mathrm{~m}_{\mathrm{pi}} \dot{\mathrm{x}}_{\mathrm{pi}} \Omega-\mathrm{m}_{\mathrm{pi}} \mathrm{x}_{\mathrm{pi}} \dot{\Omega}+\mathrm{m}_{\mathrm{pi}} \mathrm{r}_{\mathrm{c}} \Omega^{2} \sin \varphi_{\mathrm{i}} \\
\left(\mathrm{I}_{\mathrm{pi}} / \mathrm{r}_{\mathrm{p}}\right) \ddot{\theta}_{\mathrm{pi}}+\mathrm{F}_{\mathrm{spi}}-\mathrm{F}_{\mathrm{rpi}}=0
\end{gathered}
$$

where $F_{\mathrm{rpi}}$ is the normal contact force between the ring gear and the ith planet,

$$
\begin{gathered}
\mathrm{F}_{\mathrm{rpi}}=\mathrm{k}_{\mathrm{rpi}} \delta_{\mathrm{rpi}}+\mathrm{q}_{\mathrm{rpi}} \dot{\mathrm{d}}_{\mathrm{rpi}}, \\
\delta_{\mathrm{rpi}}=\left(\mathrm{x}_{\mathrm{r}}-\mathrm{x}_{\mathrm{pi}}\right) \cos \varphi_{\mathrm{rpi}}+\left(\mathrm{y}_{\mathrm{r}}-\mathrm{y}_{\mathrm{pi}}\right) \sin \varphi_{\mathrm{rpi}}+\mathrm{r}_{\mathrm{r}} \theta_{\mathrm{r}}-\mathrm{r}_{\mathrm{p}} \theta_{\mathrm{pi}}-\mathrm{r}_{\mathrm{c}} \theta_{\mathrm{c}} \cos \alpha_{\mathrm{rp}}, \\
\varphi_{\mathrm{rpi}}=\frac{\pi}{2}+\alpha_{\mathrm{rp}}+\varphi_{\mathrm{i}} .
\end{gathered}
$$

For the motion of the ith planet gear bearing, the inner race can be modelled as a two degree of freedom system that has translational motion in $\mathrm{x}$ and $\mathrm{y}$ directions. The equation of motion of the inner race can be written as,

$$
\begin{aligned}
& \mathrm{m}_{\mathrm{ibs}} \ddot{\mathrm{x}}_{\mathrm{ibs}}+\mathrm{F}_{\text {cpix }}-\mathrm{f}_{\mathrm{ibx}}=\mathrm{m}_{\mathrm{ibs}} \mathrm{x}_{\mathrm{ibs}} \Omega^{2}+2 \mathrm{~m}_{\mathrm{ibs}} \dot{\mathrm{y}}_{\mathrm{ibs}} \Omega+\mathrm{m}_{\mathrm{ibs}} \mathrm{y}_{\mathrm{ibs}} \dot{\Omega}+\mathrm{m}_{\mathrm{ibs}} \mathrm{r}_{\mathrm{c}} \Omega^{2} \cos \varphi_{\mathrm{i}}, \\
& \mathrm{m}_{\mathrm{ibb}} \ddot{\mathrm{y}}_{\mathrm{ibs}}+\mathrm{F}_{\text {cpiy }}-\mathrm{f}_{\mathrm{iby}}=\mathrm{m}_{\mathrm{ibs}} \mathrm{y}_{\mathrm{ibs}} \Omega^{2}-2 \mathrm{~m}_{\mathrm{ibs}} \dot{\mathrm{x}}_{\mathrm{ibs}} \Omega-\mathrm{m}_{\mathrm{ibs}} \mathrm{x}_{\mathrm{ibs}} \dot{\Omega}+\mathrm{m}_{\mathrm{ibs}} \mathrm{r}_{\mathrm{c}} \Omega^{2} \sin \varphi_{\mathrm{i}}
\end{aligned}
$$

The outer race is modelled as a two degree of freedom system that has translational motion in the $\mathrm{x}$ and $\mathrm{y}$ directions. The equation of motion of the outer race can be written as,

$$
\begin{gathered}
\mathrm{m}_{\mathrm{ibp}} \ddot{\mathrm{x}}_{\mathrm{ibp}}+\mathrm{k}_{b p}\left(\mathrm{x}_{b p}-\mathrm{x}_{p}\right)+\mathrm{c}_{b p}\left(\dot{\mathrm{x}}_{b p}-\dot{\mathrm{x}}_{p}\right)+\mathrm{f}_{\mathrm{ibx}}=\mathrm{m}_{\mathrm{ibp}} \mathrm{x}_{\mathrm{ibp}} \Omega^{2}+2 \mathrm{~m}_{\mathrm{ibp}} \dot{\mathrm{y}}_{\mathrm{ibp}} \Omega+\mathrm{m}_{\mathrm{ibp}} \mathrm{y}_{\mathrm{ibp}} \dot{\Omega}+\mathrm{m}_{\mathrm{ibp}} \mathrm{r}_{\mathrm{c}} \Omega^{2} \cos \varphi_{\mathrm{i}} \\
\mathrm{m}_{\mathrm{ibs}} \ddot{\mathrm{y}}_{\mathrm{ibp}}+\mathrm{k}_{b p}\left(\mathrm{y}_{b p}-\mathrm{y}_{p}\right)+\mathrm{c}_{b p}\left(\dot{\mathrm{y}}_{b p}-\dot{\mathrm{y}}_{p}\right)+\mathrm{k}_{b r}\left(\mathrm{y}_{b p}-\mathrm{y}_{b r}\right)+\mathrm{c}_{b r}\left(\dot{\mathrm{y}}_{b r}-\dot{\mathrm{y}}_{b r}\right)+\mathrm{f}_{\mathrm{iby}} \\
=\mathrm{m}_{\mathrm{ibp}} \mathrm{y}_{\mathrm{ibp}} \Omega^{2}-2 \mathrm{~m}_{\mathrm{ibp}} \dot{\mathrm{x}}_{\mathrm{ibp}} \Omega-\mathrm{m}_{\mathrm{ibp}} \mathrm{x}_{\mathrm{ibp}} \dot{\Omega}+\mathrm{m}_{\mathrm{ibp}} \mathrm{r}_{\mathrm{c}} \Omega^{2} \sin \varphi_{\mathrm{i}}
\end{gathered}
$$

The sprung mass is attached in the $\mathrm{y}$ direction. Its equation of motion can be written as,

$$
\mathrm{m}_{\mathrm{ibr}} \ddot{\mathrm{y}}_{\mathrm{ibs}}-\mathrm{k}_{b r}\left(\mathrm{y}_{b p}-\mathrm{y}_{b r}\right)-\mathrm{c}_{b r}\left(\dot{\mathrm{y}}_{b r}-\dot{\mathrm{y}}_{b r}\right)=0,
$$


where Fcpix and Fcpiy describe the interaction force between the ith planet bearing and the carrier arm in the $\mathrm{x}$ and $\mathrm{y}$ directions:

$$
\begin{gathered}
\mathrm{F}_{\mathrm{cpix}}=\mathrm{k}_{\mathrm{ibs}}\left(\mathrm{x}_{\mathrm{ibs}}-\mathrm{x}_{\mathrm{c}}\right)+\mathrm{q}_{\mathrm{ibs}}\left(\dot{\mathrm{x}}_{\mathrm{ibs}}-\dot{\mathrm{x}}_{\mathrm{c}}\right), \\
\mathrm{F}_{\mathrm{cpiy}}=\mathrm{k}_{\mathrm{ibs}}\left(\mathrm{y}_{\mathrm{ibs}}-\mathrm{y}_{\mathrm{c}}\right)+\mathrm{q}_{\mathrm{bbs}}\left(\dot{\mathrm{y}}_{\mathrm{ibs}}-\dot{\mathrm{y}}_{\mathrm{c}}\right),
\end{gathered}
$$

For the motion of the carrier arm, the motion equation is,

$$
\begin{gathered}
\mathrm{m}_{\mathrm{c}} \ddot{\mathrm{x}}_{\mathrm{c}}+\mathrm{k}_{\mathrm{cx}} \mathrm{x}_{\mathrm{c}}+\mathrm{q}_{\mathrm{cx}} \dot{\mathrm{x}}_{\mathrm{c}}-\sum_{\mathrm{i}=1}^{3} \mathrm{~F}_{\mathrm{cpix}}=\mathrm{m}_{\mathrm{c}} \mathrm{x}_{\mathrm{c}} \Omega^{2}+2 \mathrm{~m}_{\mathrm{c}} \dot{\mathrm{y}}_{\mathrm{c}} \Omega+\mathrm{m}_{\mathrm{c}} \mathrm{y}_{\mathrm{c}} \dot{\Omega}, \\
\mathrm{m}_{\mathrm{c}} \ddot{\mathrm{y}}_{\mathrm{c}}+\mathrm{k}_{\mathrm{cy}} \mathrm{y}_{\mathrm{c}}+\mathrm{q}_{\mathrm{cy}} \dot{\mathrm{y}}_{\mathrm{c}}-\sum_{\mathrm{i}=1}^{3} \mathrm{~F}_{\mathrm{cpiy}}=\mathrm{m}_{\mathrm{c}} \mathrm{y}_{\mathrm{c}} \Omega^{2}-2 \mathrm{~m}_{\mathrm{c}} \dot{\mathrm{x}}_{\mathrm{c}} \Omega-\mathrm{m}_{\mathrm{c}} \mathrm{x}_{\mathrm{c}} \dot{\Omega}, \\
\left(\mathrm{I}_{\mathrm{c}} / \mathrm{r}_{\mathrm{c}}\right) \ddot{\theta}_{\mathrm{c}}+\sum_{\mathrm{i}=1}^{3} \mathrm{~F}_{\mathrm{cpix}} \sin \varphi_{\mathrm{i}}-\sum_{\mathrm{i}=1}^{3} \mathrm{~F}_{\mathrm{cpiy}} \cos \varphi_{\mathrm{i}}=\mathrm{T}_{\mathrm{c}} / \mathrm{r}_{\mathrm{c}}, \\
\mathrm{T}_{\mathrm{c}}=\mathrm{k}_{\mathrm{cg}}\left(\theta_{\mathrm{c}}-\theta_{\text {out }}\right)+\mathrm{q}_{\mathrm{cg}}\left(\dot{\theta}_{\mathrm{c}}-\dot{\theta}_{\text {out }}\right),
\end{gathered}
$$

For the motion of the ring gear, the motion equation is,

$$
\begin{aligned}
& \mathrm{m}_{\mathrm{r}} \ddot{\mathrm{x}}_{\mathrm{r}}+\mathrm{k}_{\mathrm{rx}} \mathrm{x}_{\mathrm{r}}+\mathrm{q}_{\mathrm{rx}} \dot{\mathrm{x}}_{\mathrm{r}}+\sum_{\mathrm{i}=1}^{3} \mathrm{~F}_{\mathrm{rpi}} \cos \varphi_{\mathrm{rpi}}=\mathrm{m}_{\mathrm{r}} \mathrm{x}_{\mathrm{r}} \Omega^{2}+2 \mathrm{~m}_{\mathrm{r}} \dot{\mathrm{y}}_{\mathrm{r}} \Omega+\mathrm{m}_{\mathrm{r}} \mathrm{y}_{\mathrm{r}} \dot{\Omega}, \\
& \mathrm{m}_{\mathrm{r}} \ddot{\mathrm{y}}_{\mathrm{r}}+\mathrm{k}_{\mathrm{ry}} \mathrm{y}_{\mathrm{r}}+\mathrm{q}_{\mathrm{ry}} \dot{\mathrm{y}}_{\mathrm{r}}+\sum_{\mathrm{i}=1}^{3} \mathrm{~F}_{\mathrm{rpi}} \sin \varphi_{\mathrm{rpi}}=\mathrm{m}_{\mathrm{r}} \mathrm{y}_{\mathrm{r}} \Omega^{2}-2 \mathrm{~m}_{\mathrm{r}} \dot{\mathrm{x}}_{\mathrm{r}} \Omega-\mathrm{m}_{\mathrm{r}} \mathrm{x}_{\mathrm{r}} \dot{\Omega}, \\
& \left(\mathrm{I}_{\mathrm{r}} / \mathrm{r}_{\mathrm{r}}\right) \ddot{\theta}_{\mathrm{r}}+\left(\mathrm{q}_{\mathrm{rt}} / \mathrm{r}_{\mathrm{r}}\right) \dot{\theta}_{\mathrm{r}}+\left(\mathrm{k}_{\mathrm{rt}} / \mathrm{r}_{\mathrm{r}}\right) \theta_{\mathrm{r}}+\sum_{\mathrm{i}=1}^{3} \mathrm{~F}_{\mathrm{rpi}}=0,
\end{aligned}
$$

For the rotary motion of the load, the motion equation is,

$$
\mathrm{I}_{\text {out }} \ddot{\theta}_{\text {out }}=-\mathrm{T}_{\text {out }}+\mathrm{T}_{\mathrm{c}} \text {. }
$$

\section{3 Gear stiffness calculation}

Sun-planet and ring-planet tooth mesh stiffness variations and the resulting transmission errors were found to be the main internal vibration generation source for the planetary gear system. The gear mesh stiffness was calculated using the finite element method as it could provide more realistic simulations. The detailed step on how to model the gear pairs and how to calculate the mesh stiffness can be found in a previous work [35, 36]. The tooth mesh stiffness variation of a sun-planet gear pair was modelled from the isolated sun-planet FE model, as shown in Fig. 3(a). The tooth mesh stiffness variation of a ring-planet gear pair was modelled from the isolated sun-planet FE model, as shown in Fig. 3 (b). The corresponding gear mesh stiffness from the sun-planet FE model and the 
ring-planet FE model is shown in Fig. 4. From the figure, it can be seen that the gear mesh stiffness value will increase with the increase of the input loads and in this paper, a constant input load was considered to minimise the impact from a varying input load on the gear mesh stiffness. The planetary gear parameter used in this research can be found in Appendix B table 1.

(a)

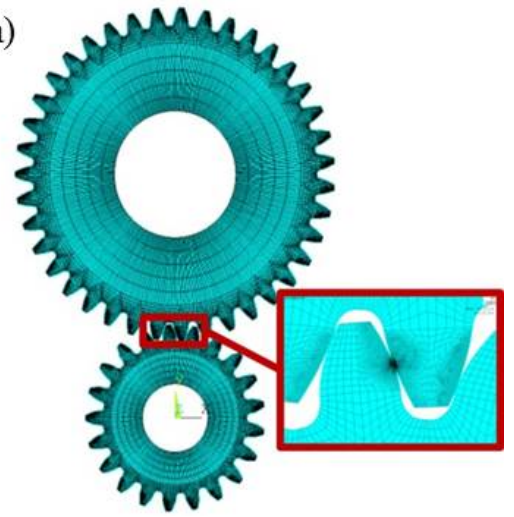

(b)

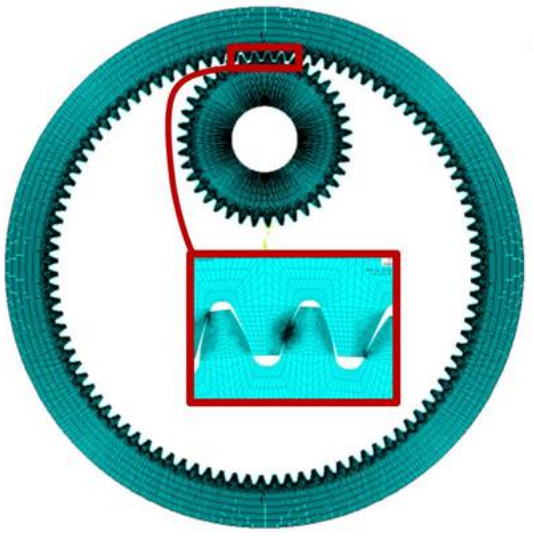

Figure 3 Planetary gear FE models, (a). Sun-planet FE model, (b) Ring-planet FE model

(a)

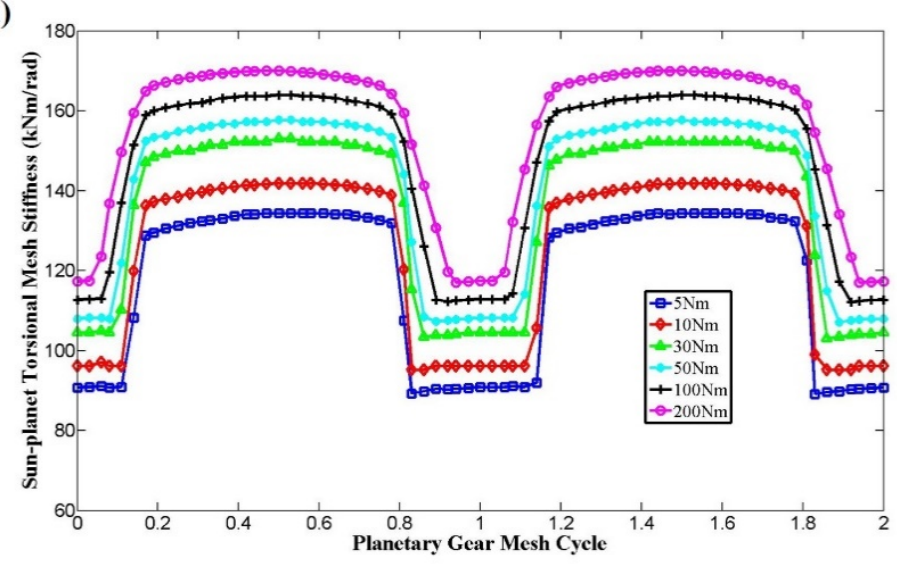

(b)

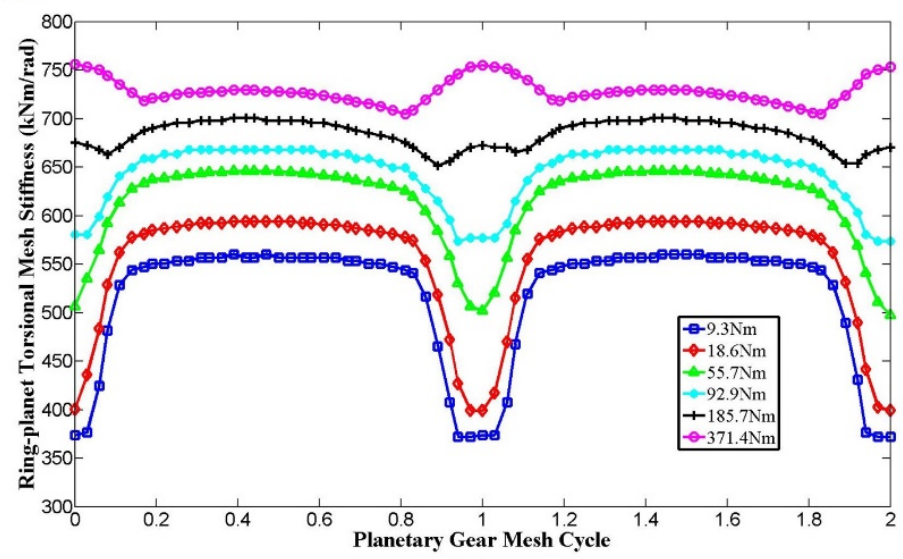

Figure 4 Planetary gear mesh stiffnesses, (a).Sun-planet mesh stiffness, (b). Ring- 


\section{planet mesh stiffness}

\section{4 Bearing stiffness calculation}

The bearing stiffness variations were found to be the main internal vibration generation source for a bearing system and the value of the bearing stiffness was estimated based on the Hertzian contact theory [37]. In the ball bearing, the rolling element contacts with the inner and outer raceway respectively. The surface of a rolling element is convex whereas the surface of the outer raceway is concave. The surface of the inner raceway is convex in the direction of motion and concave in the transverse direction. The planet bearing physical parameters used in this research can be found in appendix B table 2. A schematic representation of the rolling element contact is shown in Fig. 5.

(a)

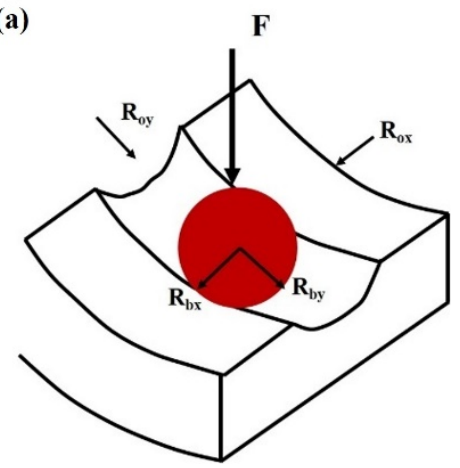

(b)

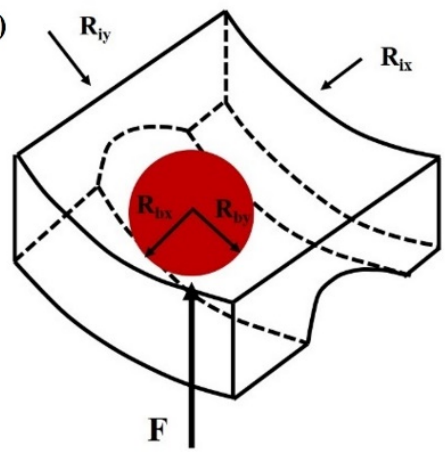

Figure 5 Planet bearing stiffness estimation models, (a). outer race model, (b). inner

\section{race model}

The total contact stiffness for the inner-ball-outer contact can be written as,

$$
k_{b}=\frac{1}{\left[\left(\frac{1}{K_{b i}^{C}}\right)^{\frac{3}{2}}+\left(\frac{1}{K_{b o}^{C}}\right)^{\frac{3}{2}}\right]^{\frac{3}{2}}} .
$$

$K_{b i}^{C}$ is the contact stiffness for the ball-inner-race contact and it can be written as,

$$
K_{b i}^{C}=\pi \mathrm{k}_{b i}^{e} E_{b i}^{\prime} \sqrt{\frac{R_{b i} \xi_{b i}}{4.5 \zeta_{b i}^{3}}}
$$

where $E_{b i}^{\prime}$ is the effective modulus of elasticity, $\mathrm{k}_{b i}^{e}, \xi_{b i}$ and $\zeta_{b i}$ are the ellipticity parameters for the ball-inner-race contact. The detailed calculation 
process of these parameters can be found in [37].

$K_{b o}^{C}$ is the contact stiffness for the bal1-outer-race contact and it can be written as,

$$
K_{b o}^{C}=\pi \mathrm{k}_{b o}^{e} E_{b o}^{\prime} \sqrt{\frac{R_{b o} \xi_{b o}}{4.5 \zeta_{b o}^{3}}}
$$

where $E_{b o}^{\prime}$ is the effective modulus of elasticity and $\mathrm{k}_{b o}^{e}, \xi_{b o}$ and $\zeta_{b o}$ are the ellipticity parameter for the ball-outer-race contact. The detailed calculation process of these parameters can be found in [37].

\section{Modelling of the planet bearing fault}

When a loaded ball encounters a spall, there will be a sudden relaxation of the loading, or, if a ball encounters a high spot or a piece of debris, a sudden increase in loading will occur. The transient forces which are produced will result in rapid accelerations of the bearing components and complex motions can occur including oscillatory contact and impacts between different components. There are three different types of localized planet bearing faults considered in this research and they are line spall on the inner race, line spall on the outer race and a fault on the rolling element, as shown in Fig. 6.
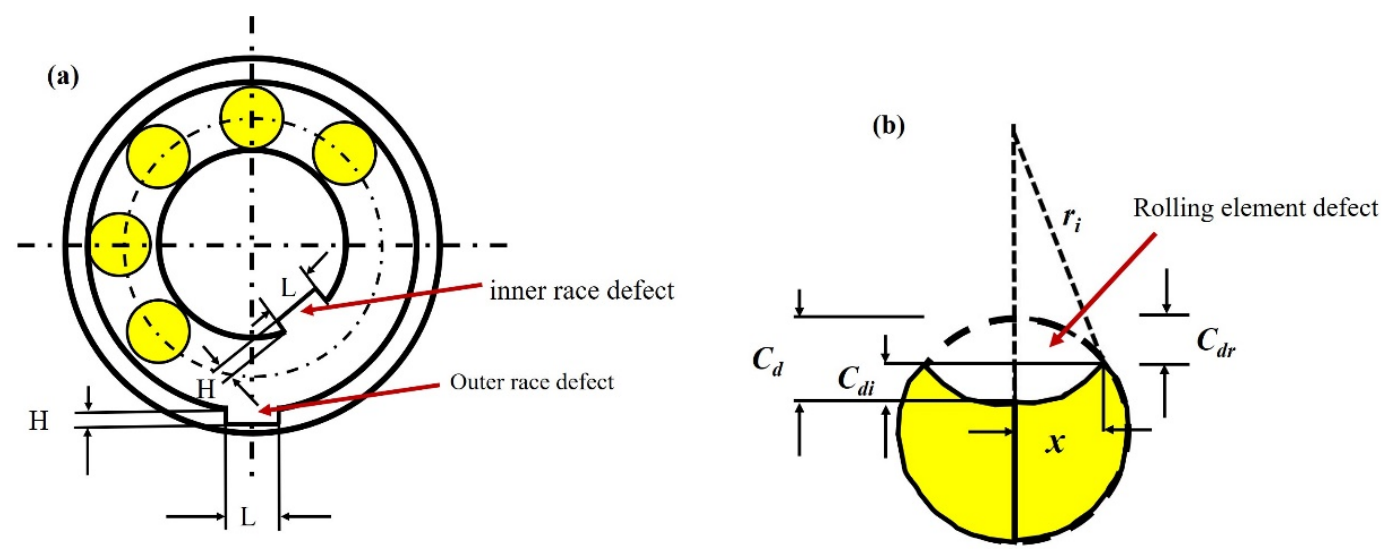

Figure 6 Planet bearing fault models, (a) localized inner and outer race faults, (b).

\section{rolling element fault}

If localized faults in inner/outer raceway or rolling elements are introduced in the bearing model, the total elastic deformation can be rewritten as,

$$
\delta_{\mathrm{ibj}}=\left(x_{i b}-x_{p i}\right) \cos \Phi_{i b j}+\left(y_{i b}-y_{p i}\right) \sin \Phi_{i b j}-c-\beta_{j} C_{d},
$$


where $C_{d}$ is the spall depth. For the inner raceway and outer raceway defect, it was modelled as a Tukey window as proposed by Liu to avoid the sudden loss of the ball raceway contact [38]. $\beta_{j}$ is the fault switch to simulate the contact loss at the predefined angular position and it determines whether the $j$ th ball/roller is inside the defected zone or not, which is defined as follows,

$$
\beta_{\mathrm{j}}=\left\{\begin{array}{ll}
1 \text { if } \Phi_{\mathrm{d}}^{\mathrm{k}}<\Phi_{\mathrm{ibj}}<\Phi_{\mathrm{d}}^{\mathrm{k}}+\Delta \Phi_{\mathrm{d}}^{\mathrm{k}} \\
0 & \text { otherwise }
\end{array},\right.
$$

where $\Phi_{\mathrm{d}}^{\mathrm{k}}(\mathrm{k}=\mathrm{in}$, out $)$ is the initial starting location of the defected zone for the inner raceway and outer raceway while $\Delta \Phi_{\mathrm{d}}^{\mathrm{k}}(\mathrm{k}=\mathrm{in}$, out) is the angular distance of the defected zone for the inner raceway and outer raceway. As the model was defined in the carrier arm rotating reference frame, the inner race defect is fixed in location between $\Phi_{\mathrm{d}}^{\text {in }}$ and $\Phi_{\mathrm{d}}^{\text {in }}+\Delta \Phi_{\mathrm{d}}^{\text {in }}$. The rotating speed of the outer race defect is the same as the planet gear rotating speed relative to the carrier arm, i. e. $\Phi_{d}^{\text {out }}=\omega_{p}^{c} t+\Phi_{d 0}^{\text {out }}$. It should be noted that the planetary gear bearing motion in this model is opposite to that of the fixed axis gear bearing motion, where the outer race is fixed in location and the inner race rotates with the rotor.

One thing that should be noted is the locations of the inner and outer race localized faults as every bearing has its own loading zone. This is illustrated in Fig. 7 (a) \& (b), where the $1^{\text {st }}$ planet bearing has been taken as one example. The radial load zone will be primarily determined by the sun-planet and ringplanet gear meshing forces. Fig. 7 (a) shows the free body diagram of the $1^{\text {st }}$ planet gear. The magnitude of sun-planet mesh force $F_{p s}$ is $T / R_{s}$ with an angle $a$ sp measured from the vertical direction. The magnitude of ring-planet gear mesh force $\mathrm{F}_{\mathrm{pr}}$ is also $\mathrm{T} / \mathrm{R}_{\mathrm{s}}$ with an angle $\mathrm{a}_{\mathrm{rp}}$ measured from the vertical direction. From the planetary gear design, we know that $a_{\mathrm{sp}}$ should be equal with $a_{\mathrm{rp}}$. Therefore, the resultant planet bearing force will be in the vertical direction and the resultant bearing loading distribution is shown in Fig. 7 (b). According to Strikeck, if ball bearings have zero clearance and are subjected to a simple radial load, the loading angle will be between $0^{\circ}$ and $-180^{\circ}$ in this case [39]. 
If the localized fault was seeded outside this loading zone, as indicated by position 1, it would generate a barely noticeable effect on the vibration response, while if the localized fault was positioned inside the loading zone, as indicated by position 2, it would generate a significant effect on the vibration response. Similarly, Fig. 7 (c) shows the load distribution zone for each planet bearing in the system.

(a) $1^{\text {st }}$ planet gear

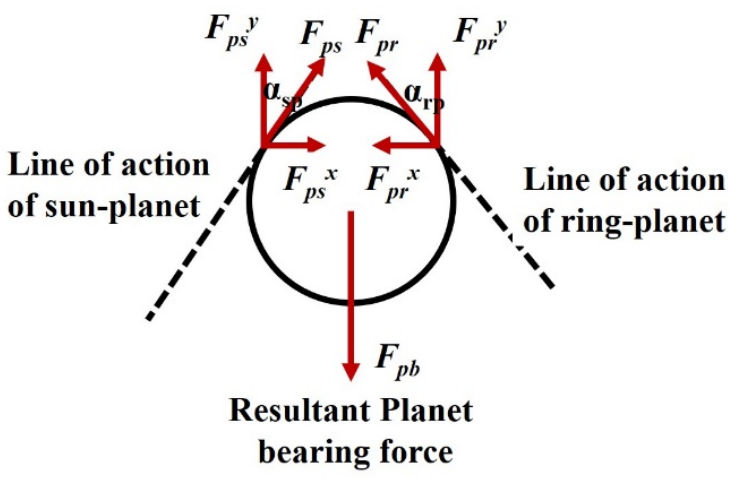

(c)

$1^{\text {st }}$ planet bearing

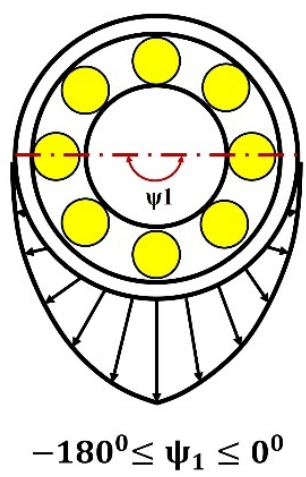

(b)

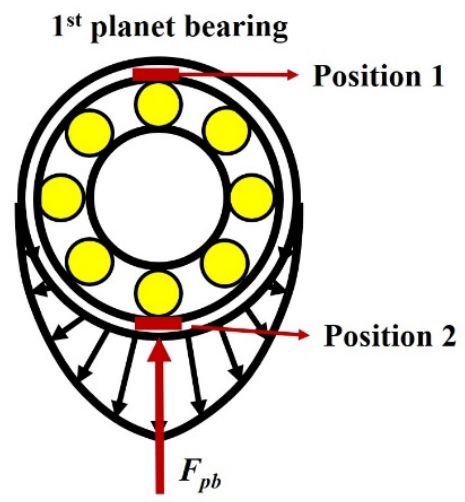

Resultant Planet gear force

$3^{\text {rd }}$ planet bearing

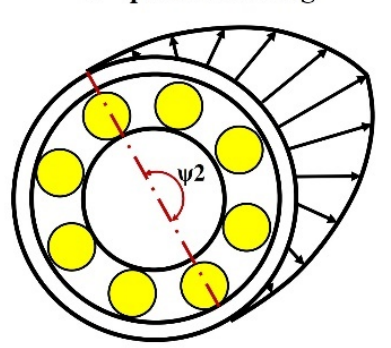

$-60^{\circ} \leq \Psi_{2} \leq 120^{\circ}$

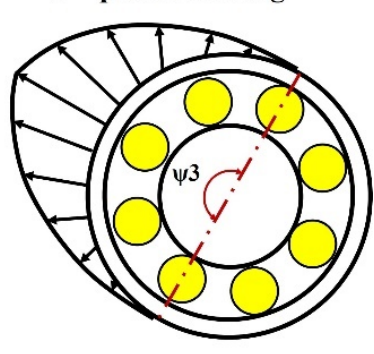

$60^{0} \leq \Psi_{3} \leq 240^{\circ}$

Figure 7 The illustration of the fault position, (a) free body diagram of the planet gear,

(b) load distribution of the planet bearing, (c) load distribution for each planet bearing A localized defect in the ball rotates at the same speed as the rolling ball, which can be calculated as,

$$
\omega_{\text {ispin }}=\frac{\omega_{i o}-\omega_{i i}}{2} \frac{D_{p}}{D_{b}}\left(1-\left(\frac{D_{b}}{D_{p}} \cos \alpha\right)^{2}\right) .
$$

The position of the spall can be defined as, 


$$
\Phi_{\mathrm{ib}}=\omega_{\text {ispin }} \mathrm{t}+\Phi_{\mathrm{ib} 0} .
$$

The angular widths of the fault for the inner and outer race contact are given as,

$$
\begin{aligned}
& \Delta \Phi_{i b o}=\frac{2 x}{r_{o}} \text { (angular width of the fault as sensed by the outer race), } \\
& \Delta \Phi_{i b i}=\frac{2 x}{r_{i}} \text { (angular width of the fault as sensed by the inner race), }
\end{aligned}
$$

where $r_{o}$ is the outer race radius and $r_{i}$ is the inner race radius. The loss of contact is detected for only the faulty rolling element $k$, and this is done twice for each complete rotation of that rolling element, i.e. when it is in touch with the inner race and with the outer race. When the spall element is in touch with the outer race, the net change in the contact $C_{d}$ is the difference between the rolling element movement and the outer race movement. This is due to the fact that the outer race moves downwards and so does the rolling element and the contact can be calculated as,

$$
\mathrm{C}_{\mathrm{d}}=\mathrm{C}_{\mathrm{dr}}-\mathrm{C}_{\mathrm{do}},
$$

where $C_{d r}$ is the rolling element movement and $C_{d o}$ is the outer race movement. They can be calculated as,

$$
\begin{gathered}
C_{d r}=\frac{D_{b}}{2}-\sqrt{\left(\frac{D_{b}}{2}\right)^{2}-x^{2}}, \\
C_{d o}=r_{o}-\sqrt{r_{o}^{2}-x^{2}} .
\end{gathered}
$$

When the spall is in contact with the inner race, the net change in the contact $C_{d}$ is the sum of the rolling element movement and the inner race movement. This is due to the fact that the inner race moves downward while the rolling element moves upward and the contact can be calculated as,

$$
\mathrm{C}_{\mathrm{d}}=\mathrm{C}_{\mathrm{dr}}+\mathrm{C}_{\mathrm{di}},
$$

where $\mathrm{C}_{\mathrm{di}}$ is the inner race movement and it can be calculated as,

$$
\mathrm{C}_{\mathrm{di}}=r_{i}-\sqrt{r_{i}^{2}-x^{2}} .
$$

Therefore, the contact deformation due to the rolling element spall contact with the inner and outer race can be written as, 


$$
\boldsymbol{\beta}_{\mathrm{j}} \mathbf{C}_{\mathrm{d}}=\left\{\begin{array}{cr}
\mathbf{0} & \mathbf{j} \neq \mathbf{k} \\
\mathbf{C}_{\mathrm{dr}}-\mathbf{C}_{\mathrm{do}} & \text { if } \mathbf{0}<\boldsymbol{\Phi}_{\mathrm{ibj}}<\Delta \boldsymbol{\Phi}_{\mathrm{ibo}} \\
\mathbf{C}_{\mathrm{dr}}+\mathbf{C}_{\mathrm{di}} & \text { if } \pi<\boldsymbol{\Phi}_{\mathrm{ibj}}<\boldsymbol{\pi}+\Delta \boldsymbol{\Phi}_{\mathrm{ibi}} \\
\mathbf{0} & \text { otherwise }
\end{array}\right\} \mathbf{j}=\mathbf{k}
$$

\section{Numerical simulation and result analysis}

\section{1 Planet bearing characteristic frequencies}

For a planet bearing in a planetary gearbox, its inner race is usually connected to the planet carrier, and its outer race is connected to the planet gear. Therefore, the planet bearing motion is a complex superposition of the revolution around the sun and ring gear common axis and its spinning around the planet axis. This section develops the planet bearing fault characteristic frequencies. If $f_{c}$ is the carrier arm absolute rotating frequency, the planet gear absolute rotating frequency is,

$$
f_{p}=1+\frac{Z_{r}}{Z_{p}} f_{c} .
$$

As discussed previous, the inner race of the planet bearing is connected to the carrier arm and the outer race of the planet bearing is connected to the planet gear, therefore, the inner race absolute rotating frequency and the outer race absolute rotating frequency can be calculated as,

$$
\begin{gathered}
f_{i}=f_{c}, \\
f_{o}=f_{p} .
\end{gathered}
$$

Given the diameter of a rolling element Db, the bearing pitch diameter Dp, the contact angle $a$, the absolute rotating frequency of the rolling element cage as well as the absolute ball spin frequency can be calculated as by the equation given by Howard [23]. However, if all the frequencies were measured in the carrier arm rotating frame, the inner race becomes stationary and the outer race relative rotating frequency becomes,

$$
f_{o}^{c}=f_{p}-f_{c} .
$$

The rolling element cage rotating frequency becomes, 


$$
\mathrm{f}_{c g}^{c}=\frac{1}{2}\left(1+\frac{D_{b}}{D_{p}} \cos \alpha\right) f_{o}^{c} .
$$

The rolling element rotating frequency becomes,

$$
f_{b}^{c}=\frac{D_{p}}{2 D_{b}}\left[1-\left(\frac{D_{b}}{D_{p}} \cos \alpha\right)^{2}\right] f_{o}^{c} .
$$

If the localized fault exists on the outer race of a planet bearing, the characteristic frequency of the outer race fault measured in the rotating frame can be calculated as,

$$
f_{b p f o}^{c}=\frac{n_{b}}{2}\left(1-\frac{D_{b}}{D_{p}} \cos \alpha\right) f_{o}^{c} .
$$

If the localized fault exists on the inner race of a planet bearing, the characteristic frequency of the inner race fault measured in the rotating frame can be calculated as,

$$
f_{b p f i}^{c}=\frac{n_{b}}{2}\left(1+\frac{D_{b}}{D_{p}} \cos \alpha\right) f_{o}^{c} .
$$

If the localized fault is on one of the rolling elements, in one spinning cycle of the rolling element, it touches both the inner and outer races, and generates impacts twice. The characteristic frequency of the rolling element fault measured in the rotating frame can be calculated as,

$$
f_{b f}^{c}=2 f_{b}^{c}=\frac{D_{p}}{D_{b}}\left[1-\left(\frac{D_{b}}{D_{p}} \cos \alpha\right)^{2}\right] f_{o}^{c} .
$$

\section{2 Results analysis for different planet bearing fault scenarios}

Instantaneous angular speed (IAS) has been emerging in the condition monitoring and diagnosis of rotating machines, such as bearings, gears, synchronous belts, etc [40-42]. The IAS signals can be naturally sampled in the angular domain and shows a greater sensitivity to different types of defects in the machine over a large bandwidth of orders [43]. The instantaneous carrier arm angular velocity in the planetary gear has been selected to diagnosis the gear faults in this 
research. In addition, the carrier arm angular velocity was also naturally free from the modulation effect caused by the transfer path. The MATLAB ode solver was used to solve the planetary gear differential equations and a constant input load was applied to the input motor, which was $T_{\text {in }}=100 \mathrm{Nm}$. The output load $T_{\text {out }}$ $=0.75 \times \dot{\theta}_{\text {out }}{ }^{2}$ was applied to the output load and it was assumed to depend on the carrier arm angular velocity. The coefficient 0.75 was used to describe the characteristics of the output load. The physical parameter of the planetary gear set used in this research can be found in Appendix B table 3. Numerical simulations were performed using the OED solver in Matlab and the chosen time intervals were $0.0001 \mathrm{~s}$. After the initial transient start-up phase has decayed away and the steady-state conditions were obtained, the system was simulated over several seconds.

Fig. 8 shows the carrier arm angular velocity signal over 16 carrier arm revolutions and there are five plots shown in the figure, corresponding to the condition of the healthy planet bearing, planet bearing with slippage, planet bearing with inner race defect, planet bearing with outer race defect and planet bearing with rolling element defect. The deterioration of these defects in the bearing system always happens gradually and the slippage of the rolling element was often observed before any significant defect happened in the components. Therefore, the defects in Fig. 8(c), Fig. 8(d) and Fig. 8(e) were simulated with the consideration of the slippage effect, as shown in Fig. 8(b). The inclusion of the defects changed the waveform in two ways. Firstly, the effect of defects was to increase the magnitude of fluctuations of the carrier arm velocity as the defects introduce some transient effect into the system. Secondly, the waveforms pattern of the defects on different components were observed to be significantly different and this is because different components have different dynamic motion, which would be expected to result in different waveform patterns once a defect occurs. The corresponding power spectrum estimation for the results in Fig. 8 can be found in Appendix C. 
(a)

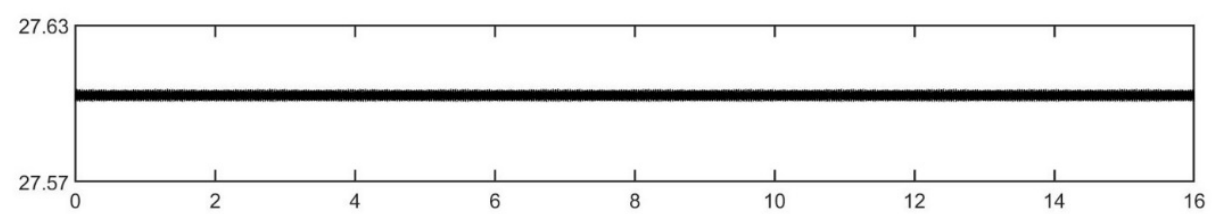

(b)

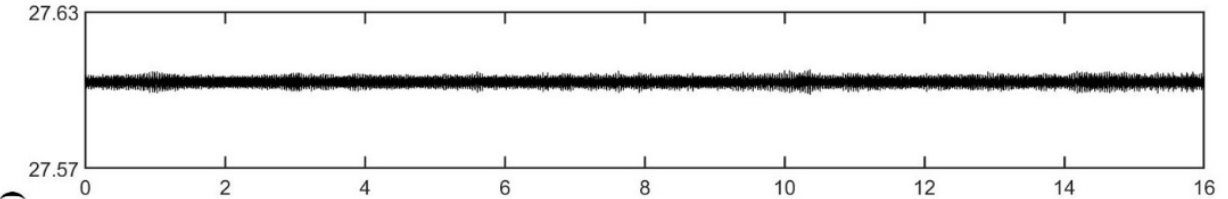

(c)

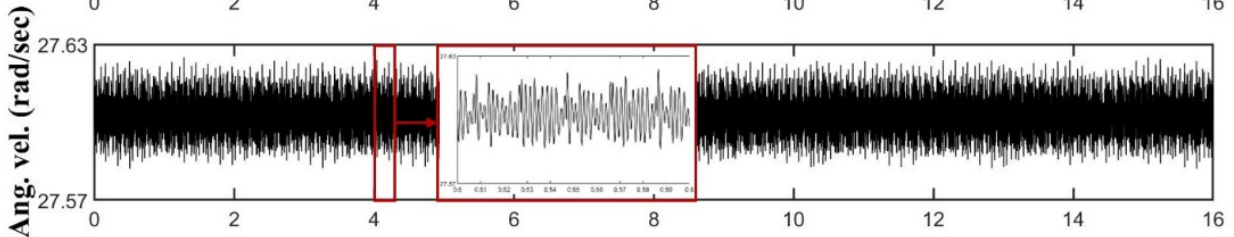

(d)

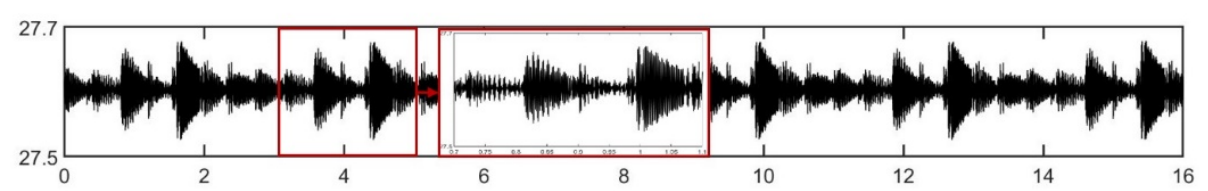

(e)

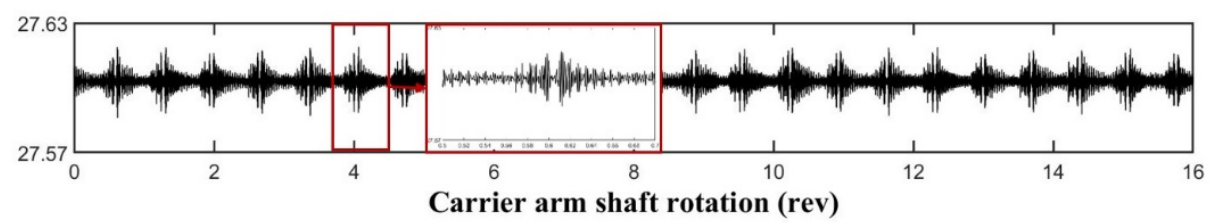

Figure 8 Carrier arm angular velocities, (a) healthy planet bearing, (b) planet bearing

with rolling element slippage, (c) planet bearing with inner race defect (d) planet

bearing with outer race defect, (e) planet bearing with rolling element defect.

The waveforms in Fig. 8 are the combination of three parts, namely the bearing signal, the gear signal and the other noise. Since the gear signal is usually much stronger, it is advantageous therefore to remove the gear signal to obtain a clear bearing signal. Gear signals are found to be deterministic and a number of methods are available to remove the deterministic part of a signal, such as linear prediction [44], adaptive noise cancellation [45], self-adaptive noise cancellation [46] and discrete separation [47]. The detailed introduction of these methods can be found in [26]. In this research, linear prediction was used to remove the gear signal and the resultant signal waveforms can be found in Fig. 9. It can be seen that the impulses due to the defects on different bearing components can be clearly observed. Similarly, the analysis of the corresponding 
power spectrum estimation for the results in Fig. 9 can be found in Appendix C.

(a)

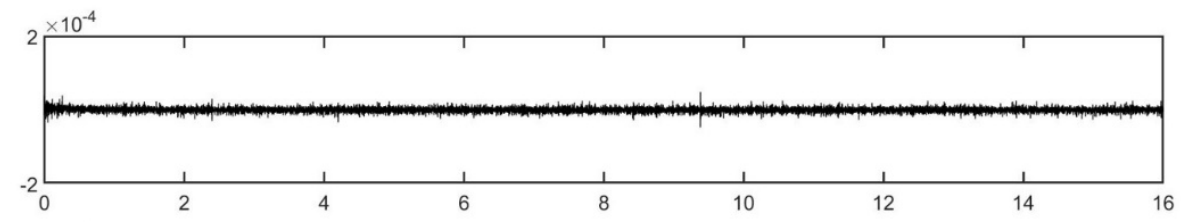

(b)

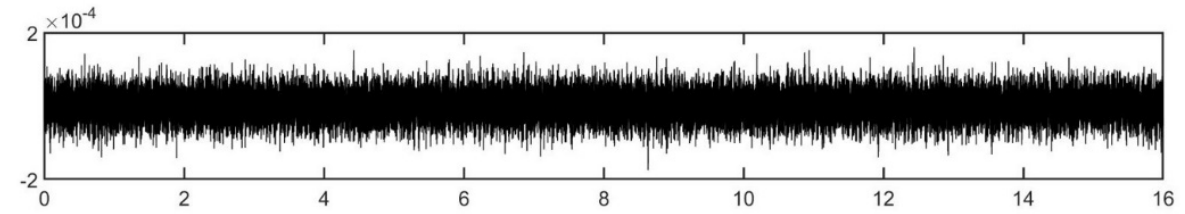

(c)

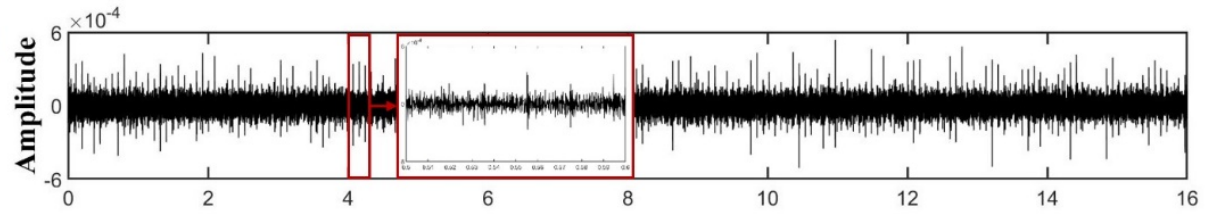

(d)

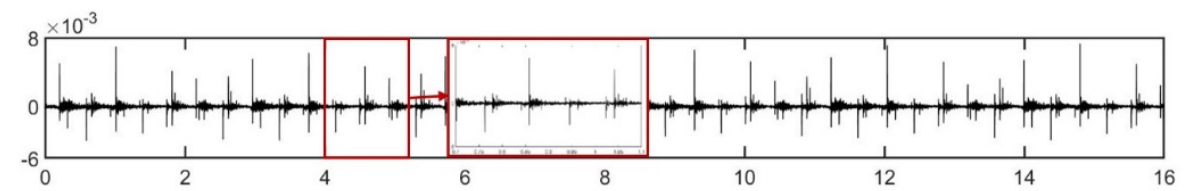

(e)

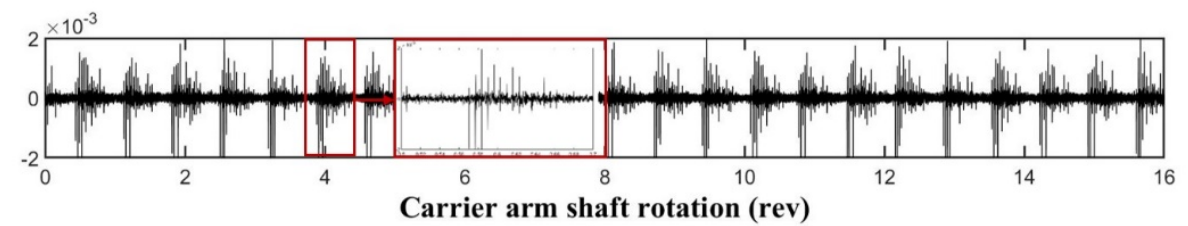

Figure 9 Extracted carrier arm angular velocities using linear prediction, (a) healthy

planet bearing, (b) planet bearing with rolling element slippage, (c) planet bearing

with inner race defect (d) planet bearing with outer race defect, (e) planet bearing with

rolling element defect.

After removing the gear signals, the bearing signals will also be contaminated by other noises and be rendered less impulsive. The minimum entropy deconvolution (MED) method can be used further to remove the effect of the transmission path [48]. This method was first proposed by Wiggins [49] for use in seismic analysis and it is designed to find an inverse filter that counteracts the effect of the transmission path by assuming the original excitation was impulsive. The obtained bearing signal waveforms can be found in Fig. 10 and their analysis of the corresponding power spectrum estimation for the results can be found in Appendix C. 
(a)

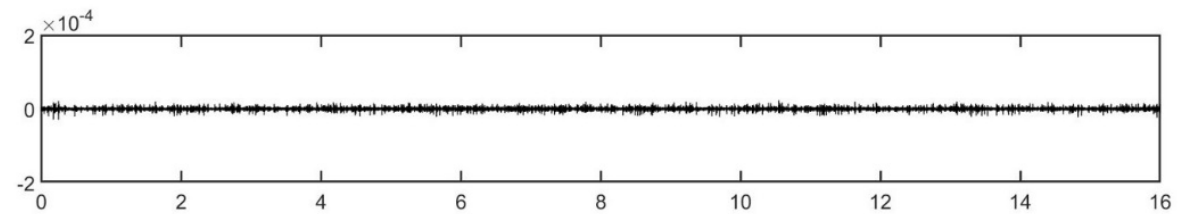

(b)

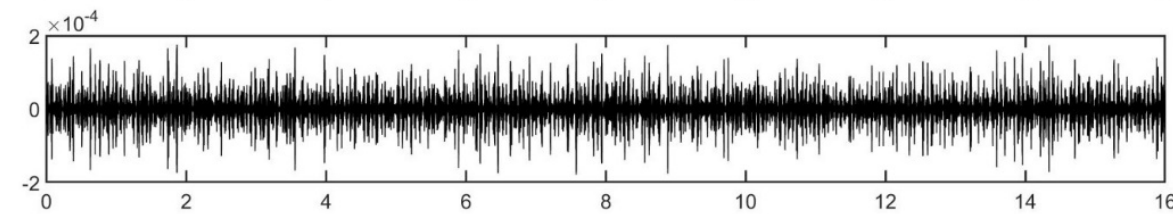

(c)

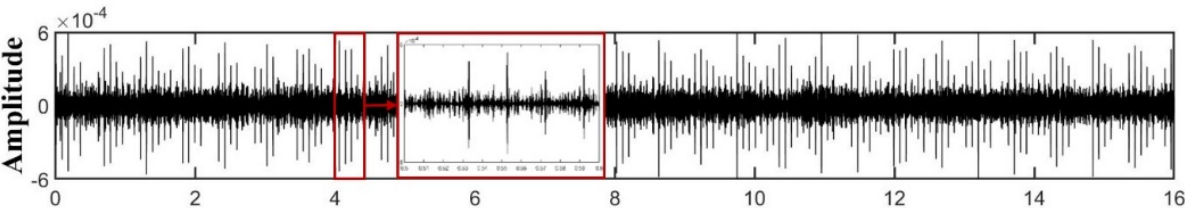

(d)

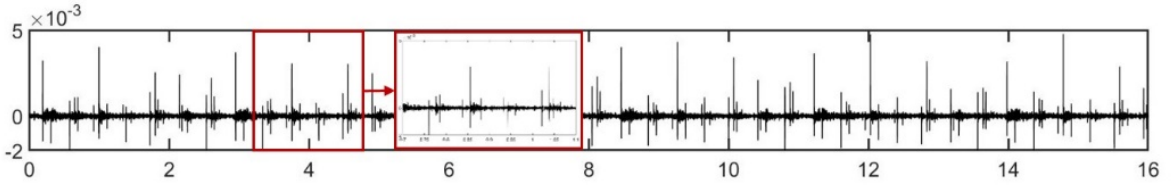

(e)

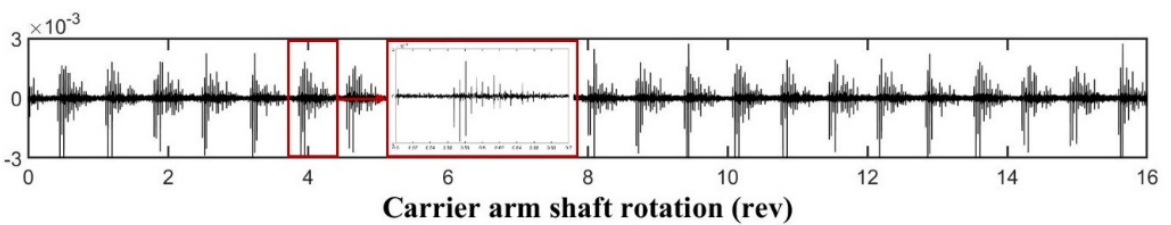

Figure 10 Extracted carrier arm angular velocities using MED, (a) healthy planet

bearing, (b) planet bearing with rolling element slippage, (c) planet bearing with inner race defect $(\mathrm{d})$ planet bearing with outer race defect, (e) planet bearing with rolling

\section{element defect.}

A comparison of the kurtosis values of the raw signals in Fig. 8, the kurtosis values of the resultant signals after linear prediction in Fig. 9 as well as the kurtosis values of the bearing signals after MED in Fig. 10 can be found in table 1. From the table, it can be seen that significant enhancements of the kurtosis values from the defect signals can be observed after linear prediction as the dominant gear signal has been removed. A further enhancement can also be observed after using the MED method to remove the effect of the transmission path. 
Table 1 Comparison of the kurtosis values

\begin{tabular}{lccc}
\hline & Raw signal & After linear & \\
& & prediction & \\
\hline Healthy planet bearing & 2.05 & 2.02 & 3.20 \\
Planet bearing with slippage & 2.53 & 2.97 & 4.73 \\
Planet bearing with inner race & & & \\
defect & 2.18 & 5.45 & \\
Planet bearing with outer race & & & 168.91 \\
defect & 4.24 & 122.54 & 123.89 \\
Planet bearing with ball defect & 5.48 & 109.83 & \\
\hline
\end{tabular}

After obtaining the clear bearing signals, it can be seen clearly that the bearing signal was modulated by the defects and the Hilbert MATLAB function that computes the analytic signal was used next to perform the amplitude demodulation, as shown in Fig. 11. From the figures, the amplitude modulation effect can be observed, especially in Fig. 11(d) and Fig. 11(e). 
(a)

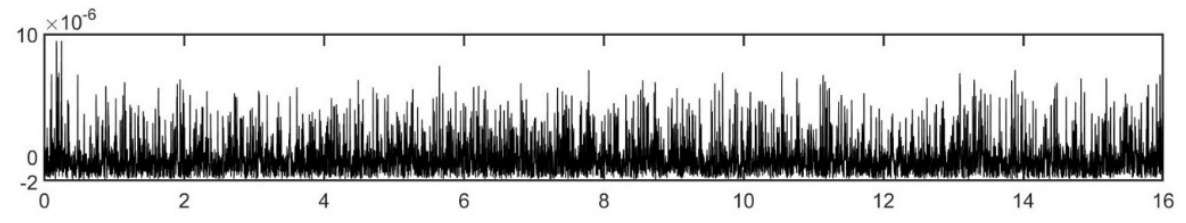

(b)

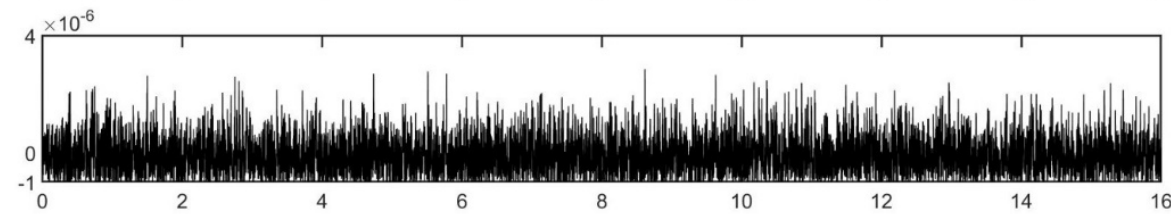

(c)

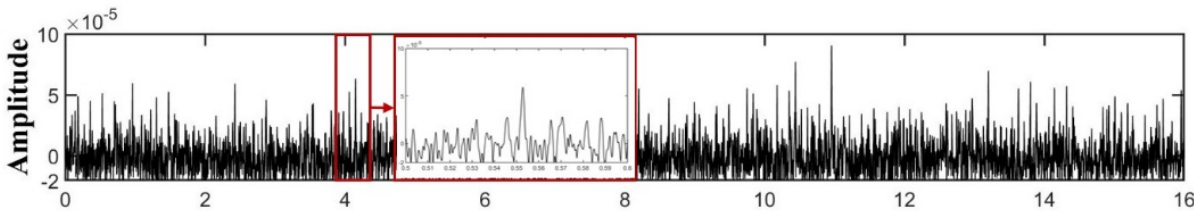

(d)

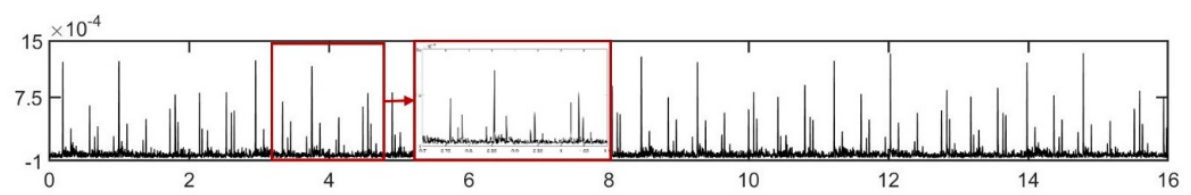

(e)

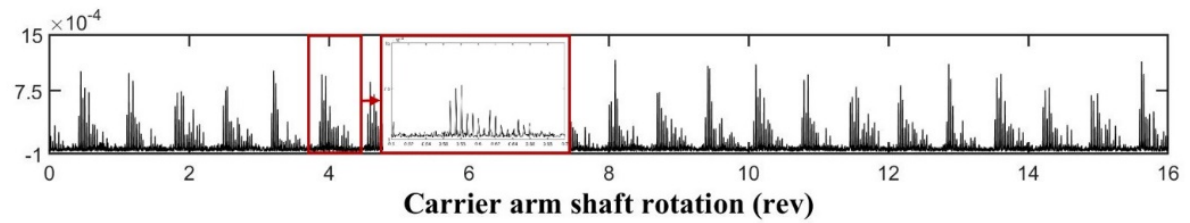

Figure 11 Carrier arm angular velocity amplitude demodulation results, (a) healthy

planet bearing, (b) planet bearing with rolling element slippage, (c) planet bearing

with inner race defect (d) planet bearing with outer race defect, (e) planet bearing with

rolling element defect.

Fig. 12 shows the amplitude demodulation spectrum of the planet bearing with inner race defect and the first 9 inner race fault frequency (BPFI) harmonics were shown in the figure. In the rotating frame, the location of the inner race defect remains stationary and did not change with the cage rotation. As every rolling element passes this location, an impulse will be excited, and the characteristic frequency of the inner race fault measured in the rotating frame can be calculated by equation (38). From the figure, the BPFI harmonics can be easily identified with little interference from other components. 


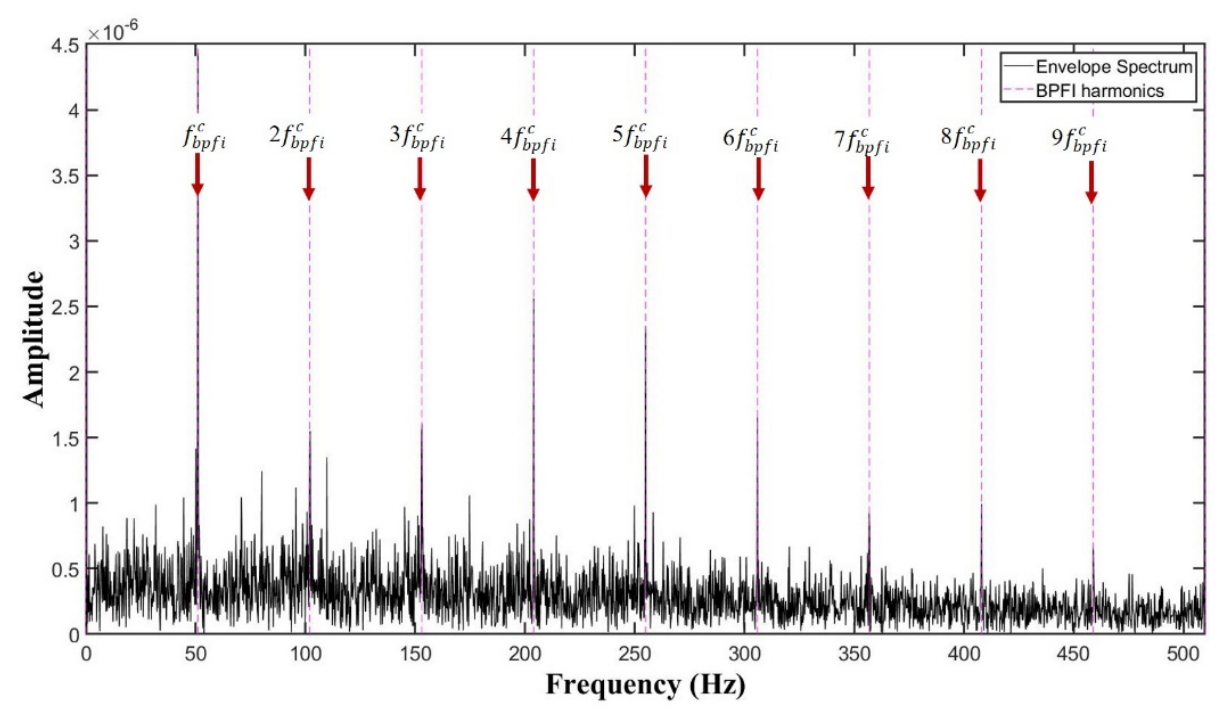

Figure 12 Planet bearing with inner race defect amplitude demodulation result

Fig. 13(a) shows the amplitude demodulation spectrum of the planet bearing with outer race defect and the first 9 outer race fault frequency (BPF0) harmonics were shown in the figure. In the rotating frame, the location of the outer race defect changes with the rotation of the outer race, with a frequency of $f_{o}^{c}$. Additionally, the rolling element also rotates with the cage, with a frequency of $f_{c g}^{c}$ in equation (37). Therefore, even though the BPFO harmonics can be identified from the figure, a large number of sidebands can also be observed. These sidebands were caused by the modulation effect from the rotation of the outer race as well as the rotation of the cage. A close look at the envelope spectrum can be found in Fig. 13(b). The third BPF0 harmonic was chosen in the figure and one can see that $3 f_{b p f o}^{c}$ is in the middle. From the middle to the left, the peaks of the sidebands are $3 f_{b p f o}^{c}-f_{c g}^{c}, 3 f_{b p f o}^{c}-f_{o}^{c}+f_{c g}^{c}, 3 f_{b p f o}^{c}-f_{o}^{c}, 3 f_{b p f o}^{c}-$ $2 f_{o}^{c}+f_{c g}^{c}, \quad 3 f_{b p f o}^{c}-2 f_{o}^{c}, \quad 3 f_{b p f o}^{c}-2 f_{o}^{c}+f_{c g}^{c}, \quad 2 f_{b p f o}^{c}+f_{o}^{c}-f_{c g}^{c}, \quad$ and $2 f_{b p f o}^{c}+f_{c g}^{c}$. From the middle to the right, the peaks of the sidebands are $3 f_{b p f o}^{c}+f_{c g}^{c}, 3 f_{b p f o}^{c}+f_{o}^{c}-$ $f_{c g}^{c}, \quad 3 f_{b p f o}^{c}+f_{o}^{c}, \quad 3 f_{b p f o}^{c}+2 f_{o}^{c}-f_{c g}^{c}, \quad 3 f_{b p f o}^{c}+2 f_{o}^{c}, \quad 3 f_{b p f o}^{c}+3 f_{o}^{c}-f_{c g}^{c}, \quad 4 f_{b p f o}^{c}-f_{o}^{c}+f_{c g}^{c}$, and $4 f_{b p f o}^{c}-f_{c g}^{c}$. 
(a)

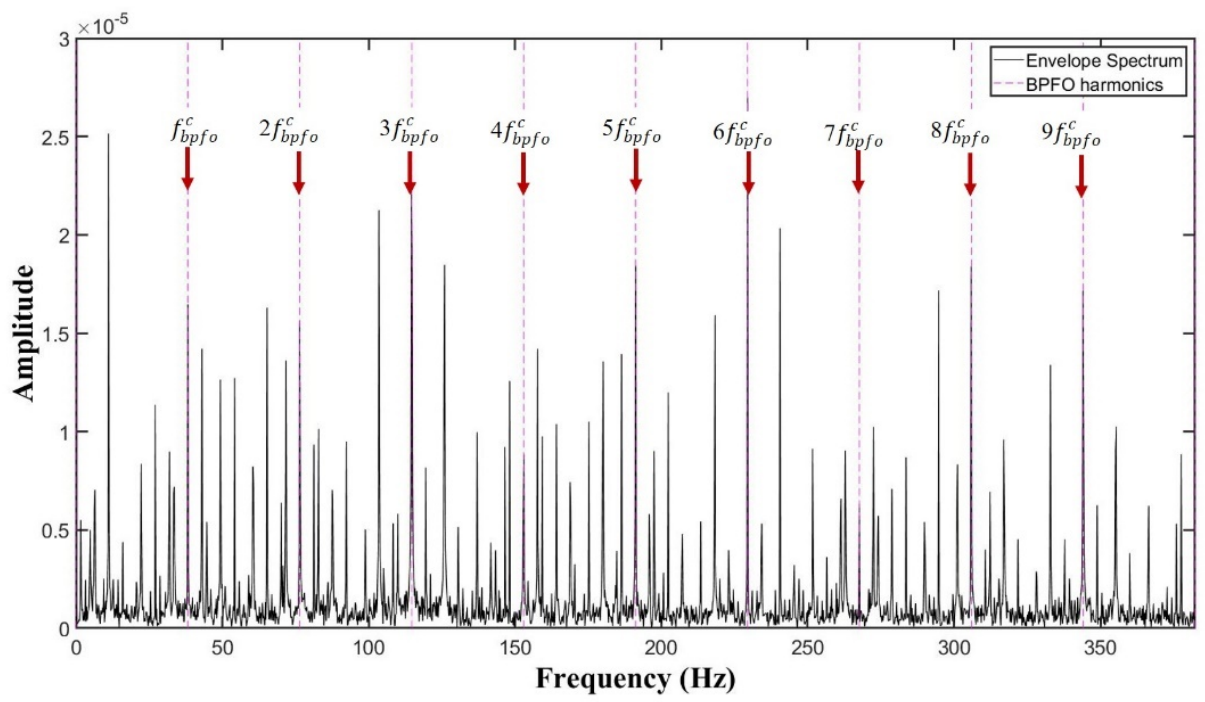

(b)

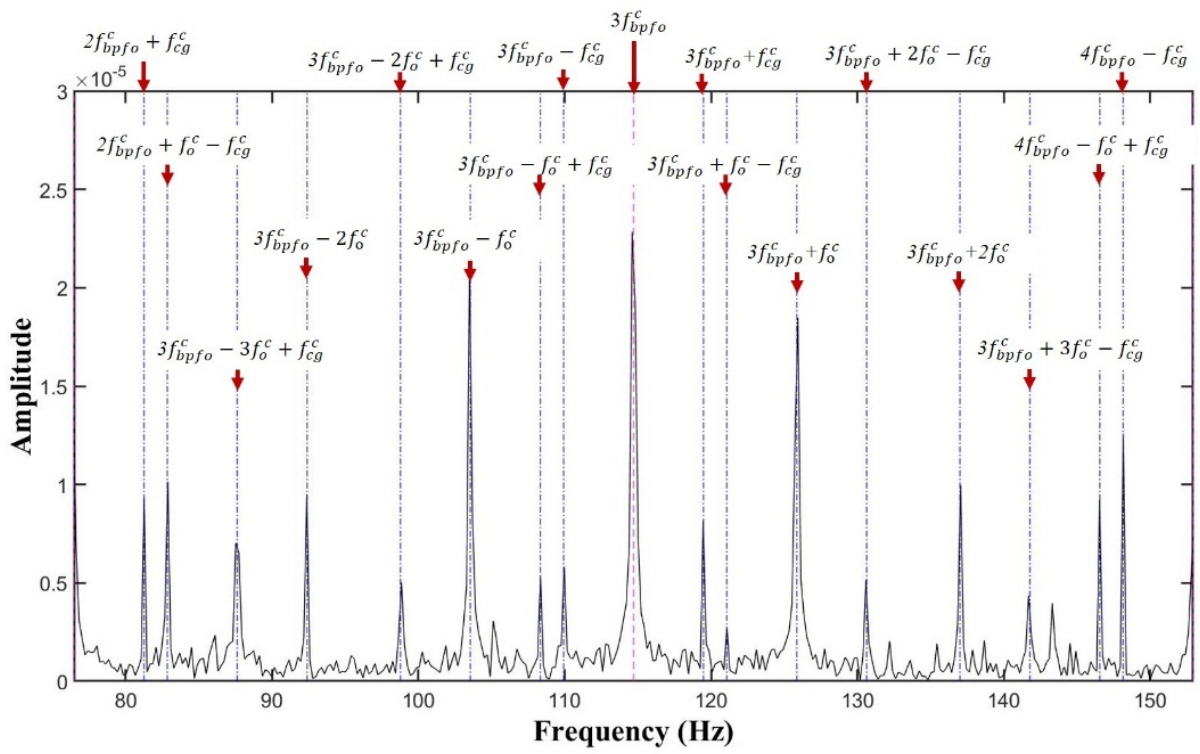

Figure 13 Planet bearing with outer race defect amplitude demodulation result, (a) the

\section{first 9 BPFO harmonics, (b) the $3^{\text {rd }}$ BPFO harmonic}

Fig. 14(a) shows the amplitude demodulation spectrum of the planet bearing with a rolling element defect and the first 9 rolling element fault frequency (BPFB) harmonics were shown in the figure. In the rotating frame, the location of the rolling element defect changes with the rotation of the cage, with a frequency of $f_{c g}^{c}$. Also, the rolling element itself rotates and the rolling element defect contacts with the inner race and outer race in a sequence within one rotation. If the impact difference from the inner race and outer race was neglected, the rolling element fault frequency can be calculated by equation (39). From the 
figure, the even BPFB harmonics can be easily identified while the odd BPFB harmonics can barely be observed. In the even BPFB harmonics, a large number of sidebands can also be observed. A close look at the envelope spectrum can be found in Fig. 14(b). The second BPFB harmonic was chosen in the figure and one can see that $2 f_{b f c}^{c}$ is in the middle. From the middle to the left, the peaks of the sidebands are $2 f_{b p f o}^{c}-f_{c g}^{c}, 2 f_{b p f o}^{c}-2 f_{c g}^{c}, 2 f_{b p f o}^{c}-3 f_{c g}^{c}, 2 f_{b p f o}^{c}-4 f_{c g}^{c}$, and so on. From the middle to the right, the peaks of the sidebands are $2 f_{b p f o}^{c}+f_{c g}^{c}, 2 f_{b p f o}^{c}+$ $2 f_{c g}^{c}, \quad 2 f_{b p f o}^{c}+3 f_{c g}^{c}, \quad 2 f_{b p f o}^{c}+4 f_{c g}^{c}$ and so on.

(a)

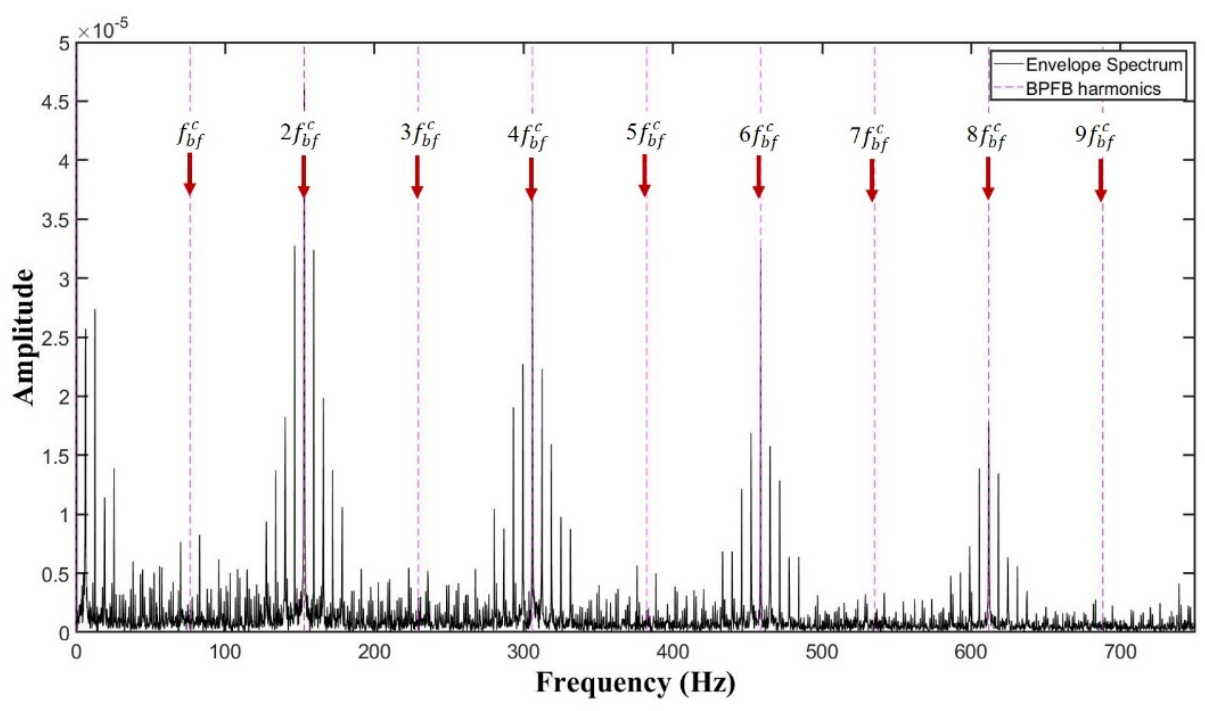

(b)

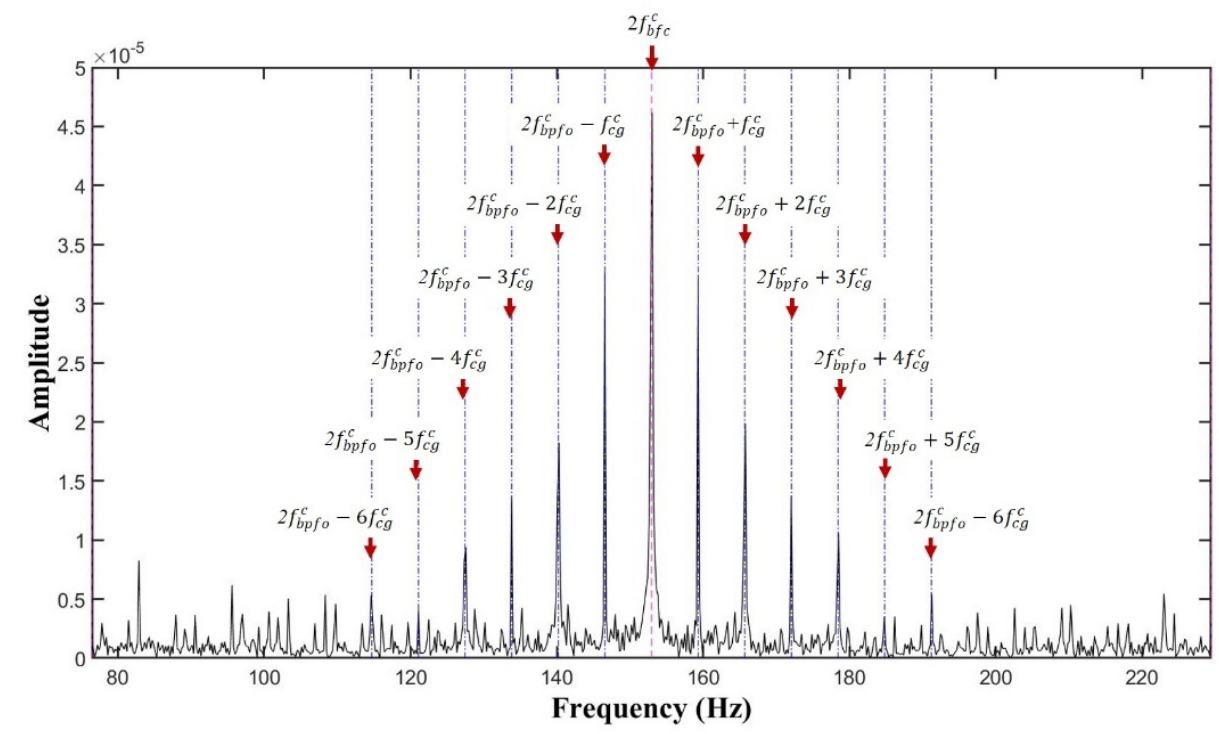

Figure 14 Planet bearing with rolling element defect amplitude demodulation result,

(a) the first 9 BPFB harmonics, (b) the $2^{\text {nd }}$ BPFB harmonic 


\section{Proposed experiment process}

\section{1 Planet bearing experiment test rig establishment}

Several experimental test rigs have already been built by other researchers to investigate the effectiveness of using instantaneous angular speed (IAS) as the diagnostic tool for rotating machinery [50-53]. In their test rigs, the incremental rotary encoder has been used to measure the rotating component instantaneous angular speed. Based on their test rig, a similar planetary gearbox test rig can also be established to demonstrate the effectiveness of using instantaneous angular speed as a diagnostic tool for the planet bearing fault, as shown in Fig. 15. In the test rig, it is made up of a servo driving motor, two planetary gearboxes as well as a hydraulic pump for loading. This proposed test rig resembles the Drivetrain Diagnostics Simulator (DDS) produced by SpectraQuest Company except the inclusion of the parallel shaft gearbox after the $2^{\text {nd }}$ planetary gearbox. The rotating speed of the servo driving motor can be controlled by the motor control panel, which allows the tested gear to operate under different speeds. The $1^{\text {st }}$ planetary gearbox is used to reduce the operating speed from the motor while the planet bearing fault can be set on the $2^{\text {nd }}$ planetary gearbox stage. As stated in [54], it is impossible to use an analog filter for an angular domain IAS signal without physically modifying the system, which makes it prone to aliasing. The author suggested that the only effective way to avoid this phenomenon is to increase the angular sensor resolution to the highest possible value. Therefore, two through-shaft rotary encoders directly connected with the shaft can be mounted on the $2^{\text {nd }}$ planetary gearbox input shaft and output shaft to ensure the capture of any speed fluctuation caused by the planet bearing faults. One possible existing through-shaft rotary encoder product with the highest resolution is the Heidenhain ERN 100 with a resolution of 5000 pulses per revolution. In this research, the carrier arm instantaneous angular speed was used to detect the planet bearing fault, therefore, the angular speed data from encoder II can be recorded for subsequent signal processing. The high 
accuracy optical encoder used in this research could ensure the angular sampling rate and measurement of the weak speed jitter induced by the planet bearing fault.

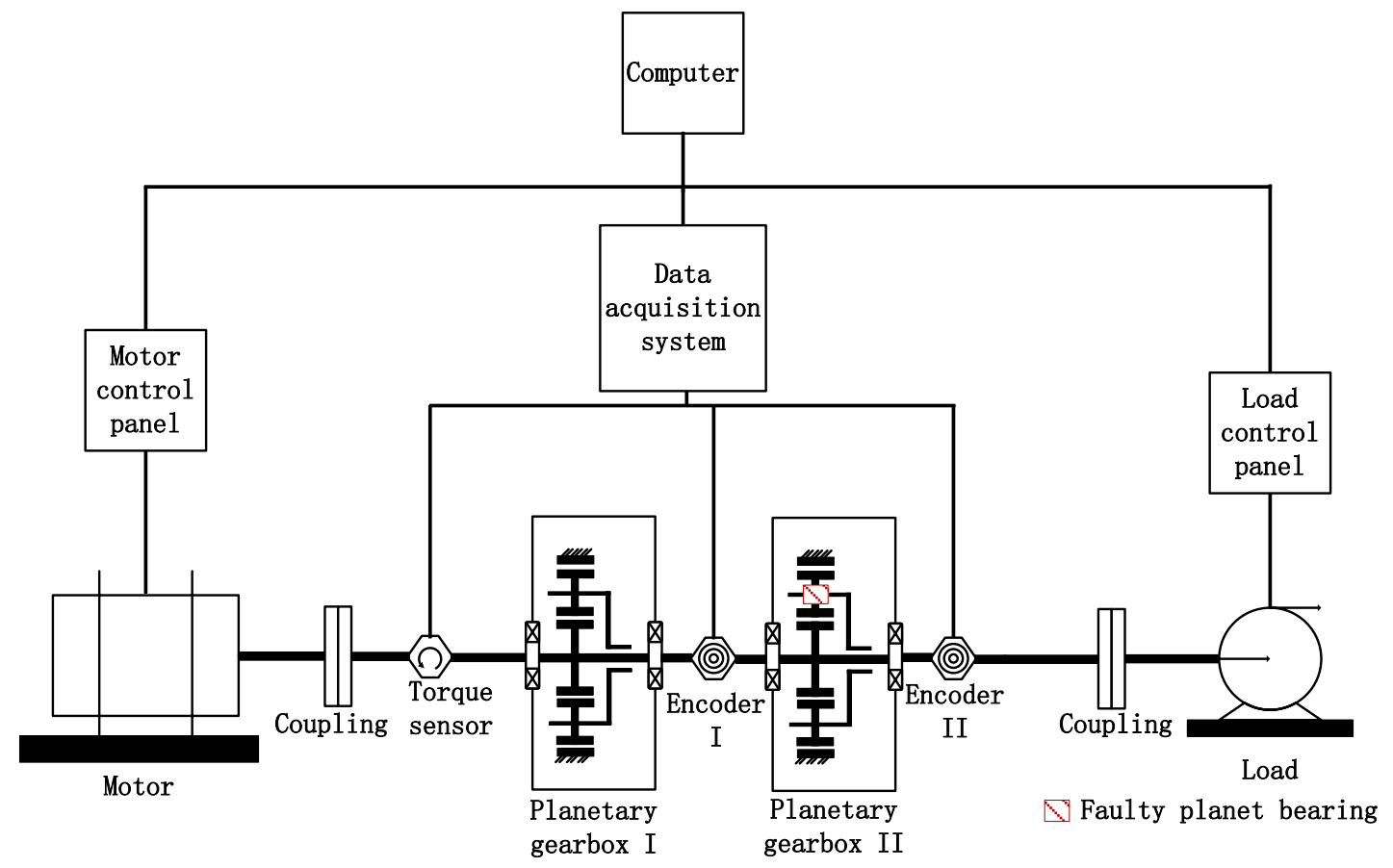

Figure 15 Proposed planet bearing experiment test rig

5. 2 Instantaneous angular speed (IAS) measurement

Numerical methods have been developed for the measurement of instantaneous angular speed in various application areas, such as the internal combustion engine. In [54], Yuhua gave a comprehensive review on the measurement of instantaneous angular speed, from the measurement principle to the performance parameter selection and later, Renaudin et al. introduced this method for bearing fault diagnosis on an industrial vehicle gearbox [50]. In [51], André et al summarized the IAS measurement method into two categories: the time dependent method and angle-position dependent method. Here, the classic elapsed time method can be used to measure the IAS signal since it is intrinsically measured in the angle domain. This method is based on the simultaneous use of an encoder and of a high-frequency counting clock. The detailed measurement principle can be found in Fig. 16. The instantaneous angular speed during an angular step can be calculated as,

$$
\overline{\omega_{i}}=\frac{\Delta \theta}{\Delta t}=\frac{2 \pi}{R} \cdot \frac{f_{\text {counter }}}{n_{c i}},
$$


where $\overline{\omega_{l}}$ is the instantaneous angular speed between two angular positions, $f_{\text {counter }}$ is the counter clock counting frequency, $R$ is the encoder resolution with $R$ impulses per revolution, and $n_{c i}$ is the counting number of clock ticks between two angular positions. Normally, a counter card (e.g. IK220 produced by Heidenhain Company) can be used as a data acquisition system to acquire the output encoder signals and the counter clock counting frequency will normally be determined once the counter card has been chosen. As indicated in [55], the counting frequency $f_{\text {counter }}$ should satisfy the following the equation to minimize the IAS measurement errors,

$$
f_{\text {counter }}>4\left[R f_{\text {shaft }}+n_{h} f_{\text {shaft }}+R \Delta f\right]
$$

where $f_{\text {shaft }}$ is the shaft rotating frequency, $n_{h}$ is the highest order of IAS components of concern and $\Delta f$ is the estimated shaft speed variation. For example, in the simulated model, the carrier arm rotating speed is $27.5 \mathrm{rad} / \mathrm{s}$, which corresponds to $4.4 \mathrm{~Hz}$. The Heidenhain ERN 100 with a resolution of 5000 pulses per revolution can be used to measure IAS. The frequency range of 20 multiples of the rotational speed can be considered with a possible speed variation value of $0.5 \mathrm{~Hz}$. Therefore, the data acquisition counting frequency should be larger than $2.5 \mathrm{kHz}$.

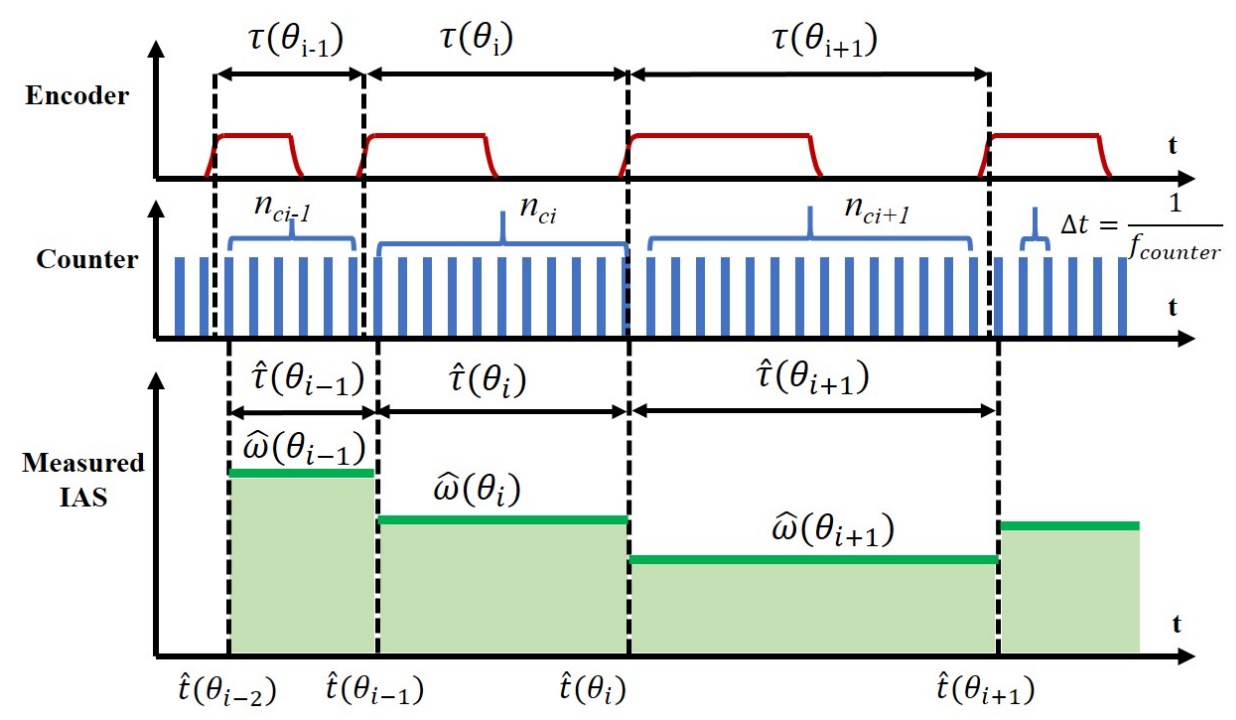

Figure 16 Elapsed time method to estimate the instantaneous angular speed principle [51] 
However, it should be noted that the measured IAS using this method is an averaged value of the actual IAS according to the time difference on angular increments, which can cause a low-pass filtering effect by the measurement. Another important point that should be emphasized is the quantization effect due to the counter clock frequency. This is because the time difference is a discrete value limited by the counter clock frequency. The detailed analysis of these two effects on the measurement of IAS can be found in [51] and the author gave valuable suggestions on how to deal with these two effects to improve the IAS measurement precision.

\section{3 Planet bearing fault diagnosis using IAS experimental considerations}

With the availability of the proposed experimental test rig in Fig. 15, the planet bearing fault experiment can be carried out with various defective bearing scenarios. To be consistent with the simulated scenarios, three cases with different faulty bearing components can be performed to demonstrate the effectiveness of the proposed method and these cases are planet bearing with faulty inner raceway, planet bearing with faulty outer raceway and planet bearing with faulty rolling element respectively. The faults on these components can be artificially created by electro erosion but care should be taken to have defects with realistic sizes and shapes. During the test, only one planet bearing on the $2^{\text {nd }}$ planetary gearbox stage should be faulty while the other planet bearings should always be healthy.

For the operation condition, the $2^{\text {nd }}$ planetary gearbox output carrier arm rotating speed should be reduced to around $27.5 \mathrm{rad} / \mathrm{s}$, which can be classified as a low speed rotating mechanical component. In [52], the low speed bearing fault detection using IAS measurement has been investigated and it was suggested that the effectiveness of using IAS for detecting bearing faults depends on both the rotating shaft speed as well as loading conditions. In their research, it was found that the lower the speed is, the more efficient the method and the fault caused variation became more apparent when the load increased. Therefore, when the planet bearing fault experiment is carried out, it would be preferable to 
have heavier torque load in the test as long as the experimental system allows. In order to have sufficient spectral resolution, the experimental test should be performed over a reasonable time period. For example, the experiment can be performed over $10 \mathrm{~min}$, which corresponds to around 50 carrier arm revolutions. The recorded data can be calculated without any normalization for the length of the signals and for all operating conditions the length of signals is kept the same. However, the comparison between these measurements would remain as relative. During the test, the output carrier arm on the $2^{\text {nd }}$ planetary gear stage angular position can be formatted as a series of discrete angular positions $\left[\mathrm{t}\left(\theta_{1}\right)\right.$, $\left.t\left(\theta_{2}\right), \ldots, t\left(\theta_{\mathrm{i}-2}\right), t\left(\theta_{\mathrm{i}-1}\right), \mathrm{t}\left(\theta_{\mathrm{i}}\right)\right]$ and at the same time, the high frequency counter can count the number of pulses between two angular positions. After the data is collected by the data acquisition system, the elapsed time data can be used to estimate the instantaneous angular speed for all the defective planet bearing scenarios.

\section{Discussion}

This paper has discussed the effectiveness of using the carrier arm instantaneous angular speed to detect the planet bearing defects as the torsional vibration has been shown to have strong potential to be an effective alternative approach for the planetary gear fault diagnosis in a previous study [14]. Lumped-parameter modelling was used in this paper to simulate the faulted planet bearing dynamic responses and there were several major assumptions in the theoretical model itself. Firstly, the friction forces between the teeth were ignored and the geometrical and profile errors were also neglected. The account of any of these effects would change the resulting gear dynamic response presented here, as has been demonstrated by other authors [56]. Another major assumption in this model is that the elasto-hydrodynamic lubrication (EHL) was not included into the bearing model. In [57], Wijnat et al. reviewed the studies related to the effect of the EHL in the rolling element bearings and it was found that the effect of EHL was moderate for medium loads and low rotational speeds and increased when 
the loads were low and the speed was high. In this study, the relative planet gear rotational speed is around $70 \mathrm{rad} / \mathrm{s}$, which corresponds to $11.7 \mathrm{~Hz}$. Therefore, only the Hertzian contact was considered here. Another important clarification that should be made here is that the treatment of slippage in this paper is based on the assumption that only the positions of the balls would change randomly while their kinematic relationship is still deterministic with respect to the speeds of the inner and outer races. As suggested in [58], there are many ways that this slippage phenomenon could be further developed and improved. For example, an improvement can be made with the consideration of the slippage memory effect, which means the rolling ball slip position at one instant is dependent on the slip at the previous instant. Based on the assumption in this research, the resultant vibration signal can be treated as a cyclostationary signal instead of a pseudo-cyclostationary signal. The purpose of all these assumptions is to ensure that the spectra of the desired torsional vibration is relatively clear and only contains the impact from the planet bearing faults. In this way, it is easier to analyse the effectiveness of using the planetary gear torsional vibration to detect the planet bearing faults.

The reason why the carrier arm instantaneous angular speed was chosen is because measuring the carrier arm torsional velocity will be much easier in practice compared to measuring the planet gear torsional velocity. The mounting of the sensors on the planet gear would change the internal structure of the planetary gear system, which is not ideal. There is usually more than one planet gear in the planetary system and another reason the carrier arm is chosen is because using one sensor on the carrier arm could provide monitoring for all the planet bearings instead of mounting multiple sensors on each planet gear. However, in this research, the aspect on how to distinguish the bearing faults on different planet gears was not investigated. It can be planned for future extensions of the work.

In the analysis, the raw signals included three main parts, i.e., the planet bearing signal, the gear signals from the sun gear, planet gear as well as from 
the ring gear and the other signals. The signals of the faults on the planet bearing were hidden in these signals and if the raw signals were analyzed directly, it would be hard to extract the planet bearing fault features. Therefore, two additional steps were added to enhance the planet bearing fault signals. Linear prediction was used firstly to remove the deterministic parts in the signal, which were mainly the gear signals. The transfer function of the linear prediction is basically an all-pole filter, which can be interpreted as an autoregressive system. After this, the MED method was used to obtain signals closer to the planet bearing fault impulses that gave rise to them. Minimizing the entropy is in fact minimizing the disorder in the signal and in turn maximizes the structured signals, which are the bearing fault impulses. A comparison of the kurtosis values between the raw signals, signals after linear prediction and signals after MED was shown in table 1 . It can be seen that the linear prediction can enhance the faulty signals up to 30 times and on the basis of linear prediction, the MED can enhance the faulty signals up to around 40 times compared with the raw signals.

The faults on the planet bearing would introduce the amplitude modulation effect into the healthy signals. In addition, the load zone interaction and other factors can also change the spectrum of the signals [33]. For the inner race defect amplitude demodulation results, the peaks of the frequency spectrum would appear in the position of the inner race fault frequency, $f_{b p f i}^{c}$, and its harmonics. There are also some sidebands that can be observed, but these components do not dominate the spectrum. For the outer race defect amplitude demodulation results, the peaks of the frequency spectrum would appear in the position of the outer race fault frequency, $f_{b p f o}^{c}$, and its harmonics. However, very strong sidebands can be observed in this spectrum, which means there are also other factors other than the outer race fault modulating the signal. By examining the detailed spectrum, it was found the sidebands can be classified into two groups, which are $n f_{b p f o}^{c} \pm k f_{c g}^{c}$ and $n f_{b p f o}^{c} \pm l f_{o}^{c} \pm k f_{c g}^{c} \quad(\mathrm{n}=1,2,3, \cdots ; 1=1,2,3, \cdots ; \mathrm{k}=1$, $2,3, \cdots)$. This indicated that the cage motion and the outer race motion have a 
significant effect on the signals. This is expected as the outer race fault rotates together with the outer race and the rolling elements rotate together with the cage. Every time the rolling element passes the position of the outer race fault, an impulse would be excited and consequently, its corresponding spectrum would be changed. For the rolling element fault, the peaks of the frequency spectrum would appear in the position of the rolling element fault frequency, $f_{b f c}^{c}$, and its harmonics. It can also be observed that the sidebands on both sides of the rolling element fault frequency were distributed symmetrically and the positions of the sidebands are $n f_{b f c}^{c} \pm k f_{c g}^{c}$. This indicated that the cage motion has a significant amplitude modulation effect on the signal. This is also expected as the fault on the rolling element rotates together with the cage.

Based on the simulation model, the influence of the planet bearing fault parameters on the resultant vibration signal can also be investigated. Take the inner raceway fault as an example here to demonstrate this effect. As the inner raceway fault has been modelled as a Tukey window in this paper, the most important fault parameter is the fault depth. Another 8 inner raceway fault scenarios with different fault depth were investigated and their kurtosis value after the MED step can be found in Fig. 17. From the figure, it is found that the kurtosis value has a decreasing trend when the fault depth is reducing, especially when the fault depth is $0.2 \mathrm{~mm}$, where a jump can be identified. This result has been further confirmed by the demodulation results from these cases, as shown in Fig. 18. From case-A to case-C, the inner raceway fault characteristic frequencies and their harmonics can be identified easily while the characteristic frequency in case-D becomes less apparent, even though the first characteristic frequency component can still be observed. From case-D until case-H, the first characteristic frequency component can be found in the figure, but their amplitude experienced a decreasing trend and it became around $5 \times 10^{-8}$ in case- $\mathrm{H}$. 


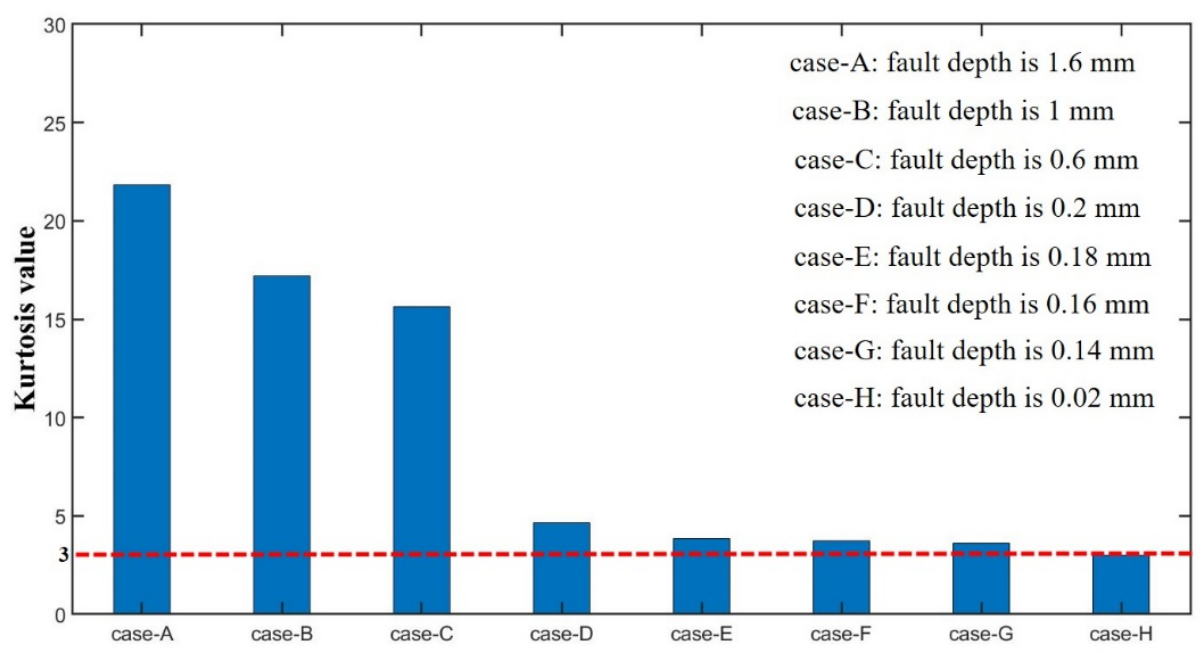

Figure 17 Summary of the kurtosis values with different inner raceway fault depth
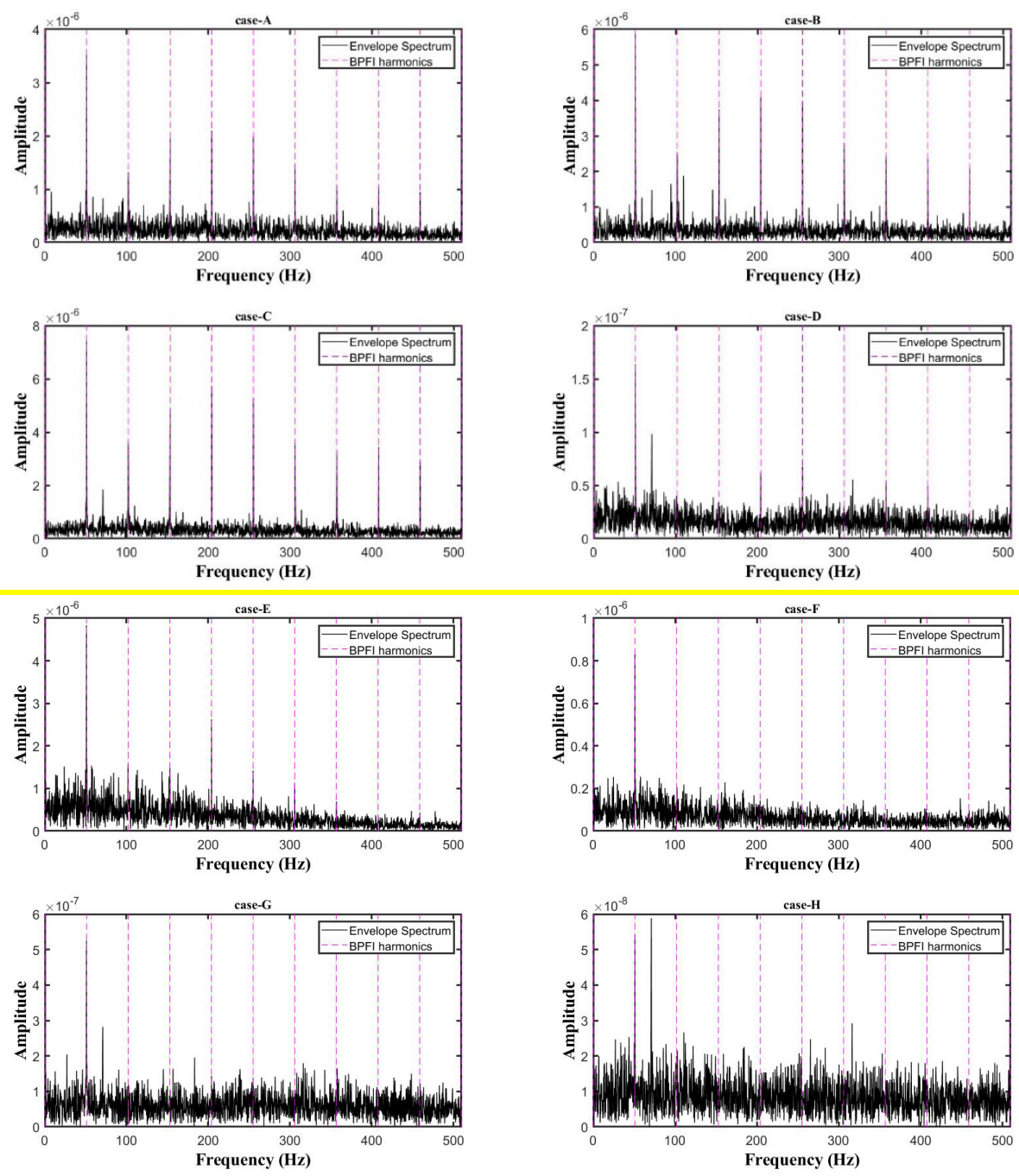

Figure 18 Amplitude demodulation results with different inner raceway fault depth 
In this research, an ideal planet bearing test rig has been proposed to show how to carry out the experimental work. This test rig has been designed based on several available transmission test rigs used in the previous paper as well as being already available on the market. For example, in previous paper [59], the DDS test rig has been widely used in their experimental work to validate their result. Also, in [53], Ming Zhao built a planetary gearbox test rig to demonstrate the effectiveness of using instantaneous angular speed to detect the gear fault. The proposed test rig includes all the basic components for the gearbox diagnostic purpose, like the planetary gear stage and the programmable driving motor and load. The instantaneous angular speed can be measured based on a sensor that can convert the angular position into the electrical signal. These sensors include optical encoders, magnetic pick-ups and hall-effect tooth wheels and so on. In this research, the through shaft optical encoder can be mounted with some cost to the low-frequency precision and it is advisable to use the highest resolution encoder available on market $[51,60]$. The optical encoder Heidenhain ERN 100 with a resolution of 5000 pulses per revolution has been proposed as a useful candidate for the measuring of IAS. As far as the authors know, this encoder is the most precise encoder available on the market and in [53], the same type of encoder has also been successfully used to measure IAS for the detection of gear faults in a planetary gearbox. Another thing that should be mentioned here is that when the test bench is built, this arrangement can also be used for the measurement of transmission error, which is an important vibration parameter for gear condition monitoring [60].

Based on the selected encoder, the elapsed time method can be used to extract the instantaneous angular speed and this method has been widely used by other researchers for both the bearing fault detection $[50-52,55]$ and the loading estimation in a diesel engine [61]. The working principle of this method has been shown in Fig. 16 and has been discussed in depth in [51]. To improve the IAS measurement accuracy, the minimum counting frequency $f_{\text {counter }}$ should be 
satisfied in equation (41). An example of the counting frequency for the Heidenhain ERN 100 with a carrier arm rotating speed of $27.5 \mathrm{rad} / \mathrm{s}$ has been given in section 5.2. Further experimental consideration has been given in section 5.3 with the detailed discussion of the input speed effect as well as the loading condition on the detectability of the bearing fault. As indicated in [52], the bearing fault would become more apparent when the operating speed is lower and a heavier load is added. All these parameters given in the example and the experimental consideration given in section 5.3 can form a solid foundation for a successful planet bearing experiment. Another thing that should be mentioned is that the elapsed time method will have speed against angle figures instead of speed against time figures, as shown in Fig. 8. However, there is a relationship between the rotation angle and the time as discussed in [62] and the resampling or interpolation strategy can often be used. In this research, the carrier arm angular speed is stationary and therefore, a linear interpolation can be used to transfer the figure with the speed against angle to the figure with the speed against time.

The experimental work on using instantaneous angular speed as a diagnostic tool can be found in several published literatures [50-53]. In [50], Renaudin et al. introduced the instantaneous angular speed method as an alternative way of bearing condition monitoring on an industrial vehicle gearbox. One interesting thing should be mentioned for that vehicle gearbox is that the outer race was the rotating part while the inner race was fixed. This arrangement is identical with the planetary gearbox arrangement used in this research, whose outer race is rotating with the planet gear while the inner race is fixed with the carrier arm in the rotating coordinate. Both researches have successfully detect the bearing characteristic frequency (or events per revolution) using the instantaneous angular speed method. In both results, the inner race spectrum (the fixed component) appeared to be clear with little sideband frequency components, as shown in Fig. 12 in this research. By contrast, the outer race spectrum in [50], (the rotating component), was shown to have a modulation effect 
due to the rotating mechanism, which was also observed in this research, as shown in Fig. 13. Another important experimental work on using IAS as a diagnostic tool for bearing fault was performed by Moustafa [52], who investigated the speed and load effect on the bearing fault detection and then further used IAS to estimate the bearing fault size. Even though the bearing arrangement is different with the arrangement in a planetary gearbox, its successful application still proved the promise and effectiveness of using IAS as a diagnostic tool. In [53], Ming Zhao et al. applied IAS to a planetary gearbox to detect the gear fault. This experiment further proved that the IAS method can be applied in a planetary gearbox and their results have been consistent with our previous paper for the gear fault detection. Another important experimental work was conducted by Dr Wade Smith from the University of New South Wales [32]. An accelerometer was mounted internally on the planet carrier to measure the vibration data. In his result, only the amplitude demodulation results from the inner race fault as we11 as the outer race fault were presented. The results in this research also showed good agreement with his results. For example, both researches have successfully identified the peaks from the amplitude demodulation frequency spectrum. In his study, he did not explore the sideband of the spectrum in detail and this research also gave an explanation for the sideband. Zhipeng proposed the signal models for the planet bearing with various faults in [33] and then experimentally validated the models. However, in his approach, the signal models were developed from the sensors mounted on the ring gear rim, therefore, in the experimental results, the carrier arm frequency also showed modulation results on the planet bearing signals. Besides this effect, the amplitude demodulation results in this research showed good agreement with his results. For example, both researchers have identified the peaks in the outer race fault frequency and its harmonics in the amplitude demodulation frequency spectrum.

\section{Conclusion}

This paper has investigated the effectiveness of using torsional vibration 
signals as the diagnostic tool for the planet bearing fault detection. The lumped-parameter model of the planet bearing in the planetary gear system was developed to obtain the dynamic response and the carrier arm instantaneous angular speed was chosen to analyse the results. The bearing faults were modelled mathematically, and they were incorporated into the developed lumped-parameter model afterwards. The linear prediction method and the MED method were used to further enhance the fault impulses generated by the planet bearing. It was found that the kurtosis value of the signal after MED increased up to 40 times compared with the raw signal. The amplitude demodulation results from the inner race fault, outer race fault and the rolling element fault were also investigated. It was found that the planetary carrier arm instantaneous angular speed measurement was an effective tool for subsequent planet bearing condition monitoring and all the relevant characteristic fault frequencies can be identified in the amplitude demodulation results.

\section{Acknowledgement}

This work was supported by the Fundamental Research Funds for the Central Universities, Natural Science Foundation of Shaanxi Province under No. 2018JZ5001

\& No. 2019JQ-548, the National Natural Science Foundation of China under (U1737211, 51805399), the National 973 Program under No. 2015CB857100.

\section{Reference}

[1] I. M. Howard, An investigation of vibration signal averaging of individual components in an epicyclic gearbox, No. ARL-PROP-R-185, Defense Science and Technology Organization (Australia), 1991.

[2] P. D. McFadden, A technique for calculating the time domain averages of the vibration of the individual planet gears and the sun gear in an epicyclic gearbox, Journal of Sound and vibration, 144(1), 1991, 163-172.

[3] P. D. McFadden, Window functions for the calculation of the time domain averages of the vibration of the individual planet gears and sun gear in an epicyclic gearbox, Journal of Vibration and Acoustics, 116(2), 1994, 179187.

[4] A. Kahraman, Natural Modes of Planetary Gear Trains, Journal of Sound and Vibration, 173(1), 1994a, 125-130. 
[5] A. Kahraman, Planetary Gear Train Dynamics, Journal of Mechanical Design, 116 (3), 1994b, 713-720.

[6] A. Kahraman, Load sharing characteristics of planetary transmissions, Mechanism and Machine Theory, 29(8), 1994c, 1151-1165.

[7] J. Lin, \& R. G. Parker, Sensitivity of planetary gear natural frequencies and vibration modes to model parameters, Journal of Sound and Vibration, $228(1)$, 1999a, 109-128.

[8] J. Lin, \& R. G. Parker, Analytical characterization of the unique properties of planetary gear free vibration, Journal of vibration and acoustics, 121(3), 1999b, 316-321.

[9] Z. Chen, \& Y. Shao, Dynamic features of a planetary gear system with tooth crack under different sizes and inclination angles, Journal of Vibration and Acoustics, 135(3), 2013a, 031004.

[10] Z. Chen, \& Y. Shao, Dynamic simulation of planetary gear with tooth root crack in ring gear, Engineering Failure Analysis, 31, 2013c, 8-18.

[11] X.H. Liang, M. J. Zuo, \& M. R. Hoseini, Vibration signal modeling of a planetary gear set for tooth crack detection, Engineering Failure Analysis, 48, 2015, 185-200.

[12] W. D. Mark, \& J. A. Hines, Stationary transducer response to planetary-gear vibration excitation with non-uniform planet loading, Mechanical Systems and Signal Processing, 23(4), 2009, 1366-1381.

[13] Z.P. Feng, \& M. J. Zuo, Fault diagnosis of planetary gearboxes via torsional vibration signal analysis, Mechanical Systems and Signal Processing, 36(2), 2013, 401-421.

[14] S. Xue, \& I. M. Howard, Torsional vibration signal analysis as a diagnostic tool for planetary gear fault detection, Mechanical Systems and Signal Processing, 100, 2018, 706-728.

[15] H. Cao, L. Niu, S. Xi, \& X. Chen, Mechanical model development of rolling bearing-rotor systems: A review, Mechanical Systems and Signal Processing, 102, 2018, 37-58.

[16] P. K. Gupta, Dynamics of rolling element bearings- part I: cylindrical roller bearing analysis, Journal of Lubrication Technology, 101(3), 1979, 293-302.

[17] P. K. Gupta, Ball bearing response to cage unbalance, Journal of Tribology, $108(3), \quad 1986,462-467$.

[18] P.K. Gupta, Cage unbalance and wear in ball bearings, Wear, 147, 1991, 93104.

[19] P. K. Gupta, Cage unbalance and wear of roller bearings, Wear, 147, 1991, 
$105-118$.

[20] S. Singh, C.Q. Howard, \& C.H. Hansen, An extensive review of vibration modelling of rolling element bearings with localized and extended defects, Journal of Sound and Vibration, 357, 2015, 300-330.

[21] N. S. Feng, E. J. Hahn, \& R. B. Randa11, Using transient analysis software to simulate vibration signals due to rolling element bearing defects, In: Proceedings of the 3rd Australian Congress on Applied Mechanics, Sydney, 2002, 689-694.

[22] N. Sawalhi, \& R. B. Randa1l, Simulating gear and bearing interactions in the presence of faults- Part I: The combined gear bearing dynamic model and the simulation of localized bearing faults, Mechanical Systems and Signal Processing, 22(8), 2008, 1924-1951.

[23] I.M. Howard, A review of rolling element bearing vibration- detection, diagnosis and prognosis, No. DST0-RR-0013, Defense Science and Technology Organization (Australia), 1994.

[24] G. Kogan, R. Klein, \& J. Bortman, A physics-based algorithm for the estimation of bearing spall width using vibrations, Mechanical Systems and Signal Processing, 104, 2018, 398-414.

[25] M. Singh, R. K. Yadav, \& R. kumar, Thrust bearing groove race defect measurement by wavelet decomposition of pre-processed vibration signal, Measurement, 46(9), 2013, 537-545.

[26] R. B. Randa11, \& J. Antoni, Rolling element bearing diagnostics- a tutorial, Mechanical Systems and Signal Processing, 25, 2011, 485-520.

[27] J. Antoni, \& R. B. Randa11, Fast Computation of the Kurtogram for the Detection of Transient Faults, Mechanical Systems and Signal Processing, $20(1), 2007, \quad 108-124$.

[28] S. Jain, Skidding and fault detection in the bearings of wind turbine gearboxes, Ph. D. Thesis, University of Cambridge, 2013.

[29] A. Moshrefzadeh, \& A. Fasana, Planetary gearbox with localized bearings and gears faults: simulation and time/frequency analysis, Meccania, 52, 2017, 3759-3779.

[30] Y. Gui, Q. Han, \& F. Chu, a vibration model for fault diagnosis of planetary gearboxes with localized planet bearing defects, Journal of Mechanical Science and Technology, 30(9), 2016, 4109-4119.

[31] F. Bonnardot, R. B. Randa11, J. Antoni, \& F. Guillet, Enhanced unsupervised noise cancellation using angular resampling application for planetary bearing fault diagnosis, In: Surveillance 5 CETIM Senlis, October, 11-13, 2004.

[32] Z. Fan, \& H. Li, A hybrid approach for fault diagnosis of planetary bearings 
using an internal vibration sensor, Measurement, 64, 2015, 71-80.

[33] Z. Feng, H. Ma, \& M. J. Zuo, Vibration signal models for fault diagnosis of planet bearings, Journal of Sound and Vibration, 370, 2016, 372-393.

[34] Z. Feng, H. Ma, \& M. J. Zuo, Amplitude and frequency demodulation analysis for fault diagnosis of planet bearings, Journal of Sound and Vibration, 382, 2016, 395-412.

[35] S. Xue, R. Entwistle, I. Mazhar, \& I. M. Howard, The spur planetary gear torsional stiffness and its crack sensitivity under quasi-static conditions. Engineering Failure Analysis, 63, 2016, 106-120.

[36] S. Xue, An investigation of gear meshing behavior of planetary gear systems for improved fault diagnosis, Ph. D thesis, Curtin University, 2016.

[37] J. Sopanen, \& A. Mikkola, Dynamic model of a deep groove ball bearing including localized and distributed defects, Part I: Theory, Proceedings of the Institution of Mechanical Engineers, Journal of Multi-body Dynamics, $217(\mathrm{k}), 2003,201-211$.

[38] J. Liu, Y. Shao, \& T.C. Lim, Vibration analysis of ball bearings with a localized defect applying piecewise response function, Mechanism and Machine Theory, 56, 2012, 156-169.

[39] T.A. Harris, \& M. N. Kotzalas, Essential concepts of bearing technology, Taylor \& Francis, 2007.

[40] J. L. Gomez, A. Bourdon, H. André, \& D. Rémond, Modelling deep groove ball bearing localized defects inducing instantaneous angular speed variations, Tribology International, 98, 2016, 270-281.

[41] B. Li, X. Zhang, \& J. Wu, New procedure for gear fault detection and diagnosis using instantaneous angular speed, Mechanical Systems and Signal Processing, 85, 2017, 415-428.

[42] A. Rivola, \& M. Troncossi, Zebra tape identification for the instantaneous angular speed computation and angular resampling of motorbike valve train measurements, Mechanical Systems and Signal Processing, 44(1), 2014, 5-13.

[43] D. Rémond, J. Antoni, \& R. B. Randall, Editorial for the special issue on Instantaneous Angular Speed (IAS) processing and angular applications, Mechanical Systems and Signal Processing, 44(1-2), 2014, 1-4.

[44] M. S. Kay, \& S. L. Marple, Spectrum analysis- a modern perspective, Proceedings of the IEEE, 69(11), 1981, 1380-1419.

[45] C. C. Tan, \& B. Dawson, An adaptive noise cancellation approach for condition monitoring of gearbox bearings, In: Proceedings of the International Tribology Conference, Melbourne, 1987. 
[46] D. Ho, Bearing diagnostics and self-adaptive noise cancellation, Ph. D thesis, University of New South Wales, 2000.

[47] J. Antoni, \& R.B. Randall, Unsupervised noise cancellation for vibration signals: Part II- a novel frequency-domain algorithm, Mechanical Systems and Signal Processing, 14, 2004, 103-117.

[48] G. L. McDonald, Q. Zhao, \& M. J. Zuo, Maximum correlated Kurtosis deconvolution and application on gear tooth chip fault detection, Mechanical Systems and Signal Processing, 33 2012, 237-255.

[49] R. A. Wiggins, Minimum entropy deconvolution, Geoexploration, 16(1-2), 1978, $21-35$.

[50] L. Renaudin, F. Bonnardot, 0. Musy, J. B. Doray, \& D. Rémond, Natural roller bearing fault detection by angular measurement of true instantaneous angular speed, Mechanical Systems and Signal Processing, 24, 2010, 1998-2011.

[51] H. André, F. Girardin, A. Bourdon, J. Antoni, \& D. Rémond, Precision of the IAS monitoring system based on the elapsed time method in the spectral domain, Mechanical Systems and Signal Processing, 44, 2014, 14-30.

[52] W. Moustafa, 0. Cousinard, F. Nolaers, K. Sghir, \& J.P. Dron, Low speed bearing fault detection and size estimation using instantaneous angular speed, Journal of Vibration and Control, 22 (15), 2014, 3413-3425.

[53] Z. Ming, J. Xiaodong, L. Jing, L. Yaguo, \& L. Jay, Instantaneous speed jitter detection via encoder signal and its application for the diagnosis of planetary gearbox, Mechanical Systems and Signal Processing, 98, 2018, 1631.

[54] L. Yuhua, G. Fengshou, H. Georgina, B. Andrew, B. Nick, \& T. Ken, The measurement of instantaneous angular speed, Mechanical Systems and Signal Processing, 19(4), 2005, 786-805.

[55] G. Fengshou, Y. Isa, L., Yuhua, H. Georgina, \& B. Andrew, An investigation of the effects of measurement noise in the use of instantaneous angular speed for machine diagnosis, Mechanical Systems and Signal Processing, 20 (6), 2006, $1444-1460$.

[56] M. Inalpolat, M. Handschuh, \& A. Kahraman, Influence of indexing errors on dynamic response of spur gear pairs. Mechanical Systems and Signal Processing, 60, 2015, 391-405.

[57] Y.H. Wi jnat, J.A. Wensing, \& G. C. Van Nijen, The influence of lubrication on the dynamic behavior of ball bearings, Journal of Sound and Vibration, $222(4)$, 1999, 579-596.

[58] N. Ghaisas, C. R. Wassgren, F. Sadeghi, Cage instabilities in cylindrical roller bearings. Journal of Tribology, 126(4), 2004, 681-689. 
[59] L. Yaguo, L. Jing, Z. Mingjian, H. Zhengjia, Condition monitoring and fault diagnosis of planetary gearboxes: A review. Measurement, 48(2), 2014, 292305.

[60] P. J. Sweeney, R. B. Randa11, Gear transmission error measurement using phase demodulation, Journal of Mechanical Engineering Science, 210, 1996, 201-213.

[61] Y. Jianguo, P. Lijun, W. Zhihua, Z. Yichen, \& Y. Xinping, Fault detection in a diesel engine by analysing the instantaneous angular speed. Mechanical Systems and Signal Processing, 15(3), 2001, 549-564.

[62] D. Remond, Practical performances of high-speed measurement of gear transmission error or torsional vibrations with optical encoders. Measurement Science and Technology, 9, 1998, 347-353.

\section{Appendix A}

The following nomenclatures were used in this paper,

c: bearing radial clearance;

$\omega_{\mathrm{ibc}}^{\mathrm{c}}$ : the ith planet bearing cage speed measured in the rotating frame;

$\omega_{\text {ibc }}$ : the absolute cage speed;

$\omega_{\text {ispin }}$ : rolling ball rotation speed on the ith planet gear;

$\omega_{p}^{c}$ : the rotating speed of the outer race defect measured in the rotating frame;

$\omega_{i i}$ : the inner race angular speed;

$\omega_{i o}$ : the outer race angular speed;

$\mathrm{n}_{\mathrm{b}}$ : number of rolling element;

$\mathrm{I}_{\mathrm{m}}, \mathrm{I}_{\mathrm{s}}, \mathrm{I}_{\mathrm{p}}, \mathrm{I}_{\mathrm{c}}, \mathrm{I}_{\mathrm{r}}, \mathrm{I}_{\text {out }}$ mass inertia of the motor, sun gear, planet gear, carrier arm, ring gear, output load;

$\mathrm{m}_{\mathrm{s}}, \mathrm{m}_{\mathrm{p} i}, \mathrm{~m}_{\mathrm{c}}, \mathrm{m}_{\mathrm{r}}$, mibs, mibr: mass of the sun, planet gear, carrier, ring gear, the planet bearing and the mass sprung;

$\theta_{\mathrm{m}}, \theta_{\mathrm{s}}, \theta_{\mathrm{p}}, \theta_{\mathrm{c}}, \theta_{\mathrm{r}}, \theta_{\text {out }}$ : angular displacement of the motor, sun gear, planet gear, carrier arm, ring gear, output load;

$\mathrm{x}_{\mathrm{j}}(\mathrm{j}=\mathrm{s}, \mathrm{pi}, \mathrm{c}, \mathrm{r}, \mathrm{ibs}, \mathrm{ibp})$ : 1inear displacement in the horizontal direction measured in the rotating frame;

$\mathrm{y}_{\mathrm{j}}(\mathrm{j}=\mathrm{s}, \mathrm{pi}, \mathrm{c}, \mathrm{r}, \mathrm{ibs}, \mathrm{ibp})$ : linear displacement in the vertical direction measured in the rotating frame;

$\mathrm{k}_{\mathrm{cp}}, \mathrm{k}_{\mathrm{cg}}$ : torsional stiffness of the input coupling and shaft and the output coupling 
and shaft;

$\mathrm{q}_{\mathrm{cp}}, \mathrm{q}_{\mathrm{cg}}$ : torsional damping of the input coupling and shaft and the output coupling and shaft;

$\mathrm{k}_{\mathrm{bp}}, \mathrm{c}_{\mathrm{bp}}$ : stiffness and damping between the planet gear and the bearing outer race;

$\mathrm{k}_{\mathrm{bs}}, \mathrm{c}_{\mathrm{bs}}$ : stiffness and damping between the carrier arm and the bearing inner race;

$\mathrm{k}_{\mathrm{sp}}, \mathrm{k}_{\mathrm{rpi}}$ : mesh stiffness of the $\mathrm{i}-\mathrm{th}$ sun-planet, ring-planet;

$\mathrm{k}_{\mathrm{b}}$ : the combined contact stiffness between the rolling element and the races;

$\mathrm{K}_{\mathrm{bi}} \mathrm{c}$ : the contact stiffness for the ball inner race contact;

$\mathrm{K}_{\mathrm{bo}_{\mathrm{o}}}{ }^{\mathrm{c}}$ : the contact stiffness for the ball-outer-race contact;

$\mathrm{E}_{b \mathrm{i}}$ ' : the inner race effective modulus of elasticity;

$\mathrm{E}_{\mathrm{bo}}{ }^{\prime}$ : the inner race effective modulus of elasticity

$\mathrm{k}_{b i}^{e}, \quad \xi_{b i}, \quad \zeta_{b i}$ : ellipticity parameter for the ball-inner-race contact;

$\mathrm{k}_{b o}^{e}, \xi_{b o}, \zeta_{b o}$ : ellipticity parameter for the ball-outer-race contact;

$\mathrm{q}_{\mathrm{spi}}, \mathrm{q}_{\mathrm{rpp}}$ : mesh damping of the i-th sun-planet, ring-planet;

$\mathrm{k}_{\mathrm{rt}}, \mathrm{q}_{\mathrm{r}}$ : stiffness and damping of ring gear in the torsional direction;

$\mathrm{r}_{\mathrm{s}}, \mathrm{r}_{\mathrm{p}}, \mathrm{r}_{\mathrm{r}}$ : base radius of the sun gear, planet gear, ring gear;

$\mathrm{r}_{\mathrm{c}}$ : radius of the circle passing through planet gear centres;

$\mathrm{r}_{\mathrm{o}}$ : bearing outer race radius

$\mathrm{r}_{\mathrm{i}}$ : bearing inner race radius;

$\mathrm{D}_{\mathrm{b}}$ : the rolling element diameter;

$\mathrm{D}_{\mathrm{p}}$ : the bearing pitch diameter;

$a$ : the planet bearing contact angle

$\mathrm{T}_{\text {in }}, \mathrm{T}_{\text {out }}$ input motor torque and output load torque;

$\delta_{\text {spi }}, \delta_{\text {rpi }}$ : relative displacement on the lines of action of i-th sun-planet, ringplanet;

$\delta_{\mathrm{ibj}}$ : the $\mathrm{jth}$ rolling element overall contact deformation on the ith planet gear;

$\varphi_{\mathrm{i}}$ : circumferential angle of $\mathrm{i}$-th planet;

$\Phi_{\mathrm{ibj}}$ : the angular position of the $\mathrm{jth}$ rolling element on the ith planet gear;

$\Phi_{\text {slip: }}$ the slippage between the ball and the race;

$\Omega$ : carrier arm rotation speed; 
$Z r$ : the number of the ring gear tooth;

$Z p$ : the number of the planet gear tooth;

$f_{p}$ : the planet gear absolute rotating frequency;

$f_{r f}$ : the ring gear characteristic fault rotational frequency;

$f_{c}$ : the carrier arm rotational frequency;

$f_{i}$ : the absolute planet bearing inner race;

$f_{o}$ : the absolute planet bearing outer race;

$f_{o}^{c}$ : the bearing outer race relative rotating frequency;

$f_{c g}{ }^{c}$ : the rolling element cage relative rotating frequency;

$f_{b}^{c}$ : the rolling element relative rotating frequency;

$f_{b p f o}$ : the characteristic frequency of the outer race fault measured in the rotating frame;

$f_{b p f i}$ : the characteristic frequency of the inner race fault measured in the rotating frame;

$f_{b f}$ : the characteristic frequency of the rolling element fault measured in the rotating frame;

$H$ : the race defect depth;

$L:$ the race defect length;

$x$ : half of the rolling element defect length 


\section{Appendix B}

Table 1 Planetary gear parameters

\begin{tabular}{llll}
\hline & Sun gear & Planet gear & Ring gear \\
\hline Number of teeth, $Z_{i}$ & $Z_{s}=21$ & $Z_{p}=39$ & $Z_{r}=99$ \\
Module, $m_{n}$ & $10 \mathrm{~mm}$ & $10 \mathrm{~mm}$ & $10 \mathrm{~mm}$ \\
Pressure angle, $\alpha_{i}$ & $\alpha_{s}=20^{\circ}$ & $\alpha_{p}=20^{\circ}$ & $\alpha_{\mathrm{r}}=20^{\circ}$ \\
Basic diameter, $d_{b i}=d_{i} \cos \alpha_{i}$ & $d_{b s}=197 \mathrm{~mm}$ & $d_{b p}=366 \mathrm{~mm}$ & $d_{b r}=930 \mathrm{~mm}$ \\
Elastic Modulus, $E$ & $210 \mathrm{MPa}$ & $210 \mathrm{MPa}$ & $210 \mathrm{MPa}$ \\
Poisson' s Ratio, $v$ & 0.3 & 0.3 & 0.3 \\
\hline
\end{tabular}

Table 2 Physical parameters of the planet bearing

\begin{tabular}{ll}
\hline & Planet bearing \\
\hline Pitch Diameter $(\mathrm{m})$ & 0.07 \\
Inner race diameter $(\mathrm{m})$ & 0.05 \\
Outer race diameter $(\mathrm{m})$ & 0.09 \\
Number of rolling element & 8 \\
Rolling element diameter $(\mathrm{m})$ & 0.01 \\
Mass (Kg) & 0.5 \\
\hline
\end{tabular}

Table 3 Physical parameters of a planetary gear set

\begin{tabular}{lllll}
\hline & Sun gear & Planet gear & Ring gear & Carrier arm \\
\hline Mass (Kg) & 2.38 & 8.22 & 22.713 & 52
\end{tabular}




\begin{tabular}{lllll} 
Mass inertia $\left(\mathrm{Kg} \cdot \mathrm{m}^{2}\right)$ & 0.01 & 0.138 & 5.99 & 2.34 \\
Bearing stiffness $(\mathrm{N} / \mathrm{m})$ & $1 \times 10^{5}$ & $\mathrm{~Kb}$ & $1 \times 10^{10}$ & $1 \times 10^{10}$ \\
Bearing damping $(\mathrm{Ns} / \mathrm{m})$ & $1 \times 10^{3}$ & $1 \times 10^{3}$ & $1 \times 10^{3}$ & $1 \times 10^{3}$ \\
\hline
\end{tabular}

\section{Appendix C}

The power spectrums for the results in Fig. 8, Fig. 9 as well as Fig. 10 have been presented in this section. Fig. C1 gives the power spectrums of the carrier arm angular velocities under different planet bearing scenarios and it can be found that the planetary gear meshing frequencies and their harmonics have dominated the spectrums in these cases except for the inner raceway fault case and the rolling element fault case. In Fig. C1(c), a set of strong frequency components caused by the inner raceway fault can also be observed beside the gear meshing harmonics. Similarly in Fig. C1(e), a set of strong frequency components caused by the rolling element can be identified in the spectrum, but with strong sidebands. 
(a)

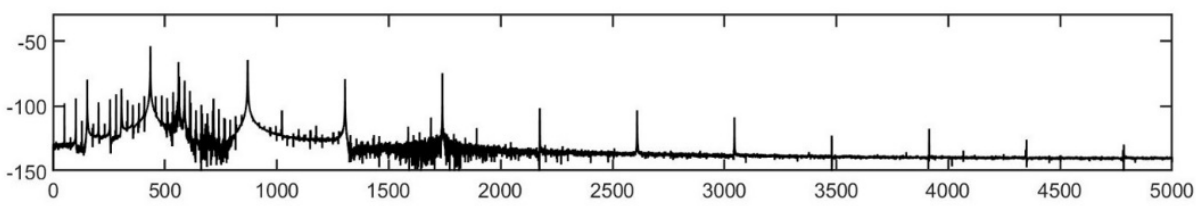

(b)

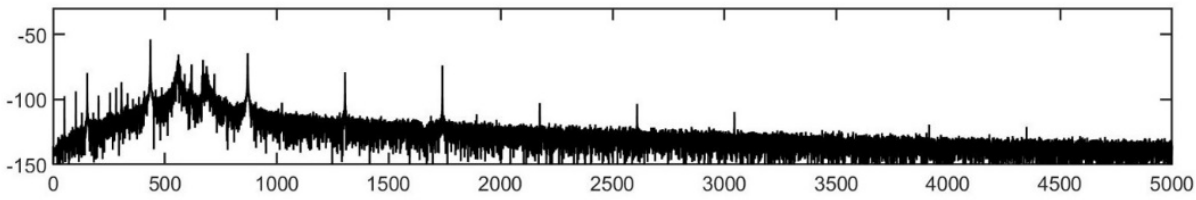

(c)

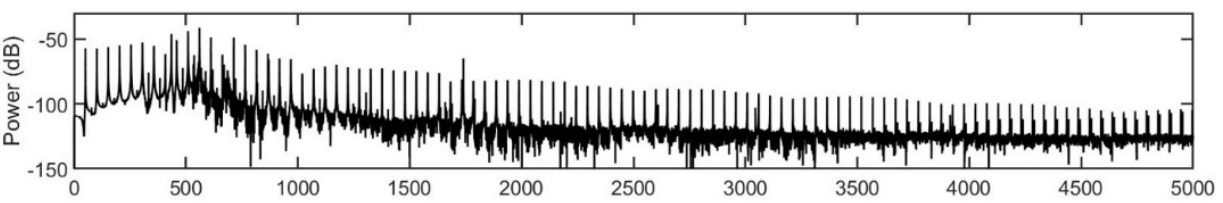

(d)

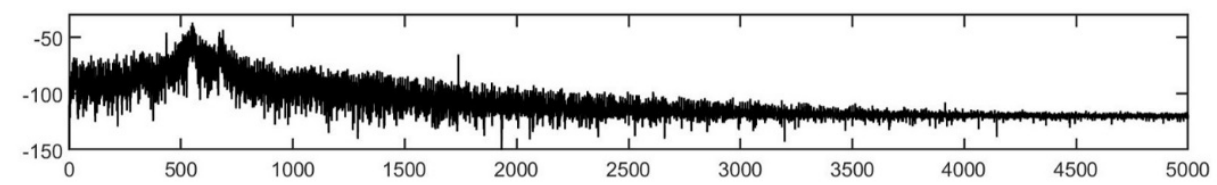

(e)

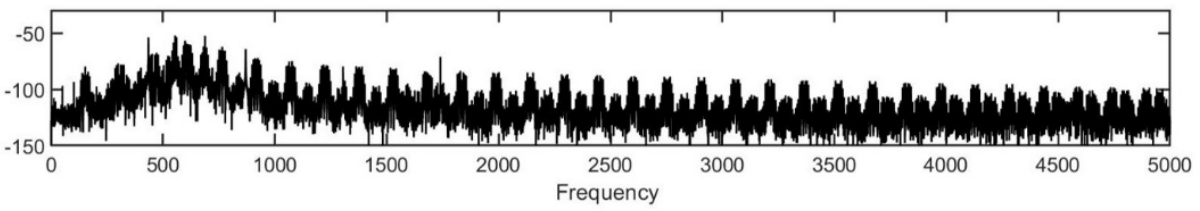

Fig. C1 Power spectrums of the carrier arm angular velocities, (a) healthy planet bearing, (b) planet bearing with rolling element slippage, (c) planet bearing with inner race defect (d) planet bearing with outer race defect, (e) planet bearing with rolling element defect

Fig. C2 presents the power spectrums of the vibration signal after using linear prediction and as expected, the planetary gear meshing frequencies and their harmonics have been eliminated from the spectrums. However, this procedure does not give a better view of the fault characteristic frequencies in the spectrum as the overall spectrum power level is almost on the same level in these figures. In Fig. C2(3), some strong frequency components can be observed. After a closer check, it is found that these components are caused by the bearing cage rotation and their spacing is equal to the bearing cage frequency. 
(a)

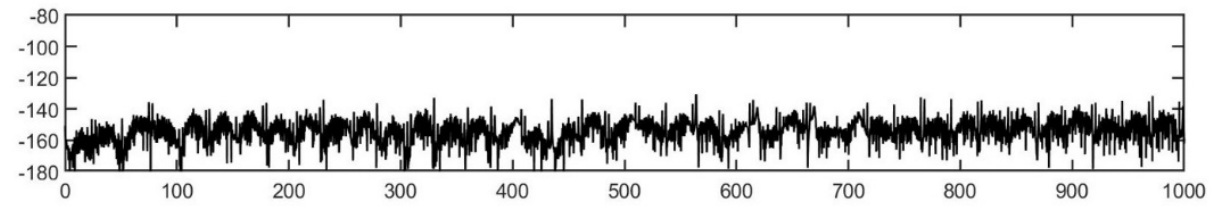

(b)

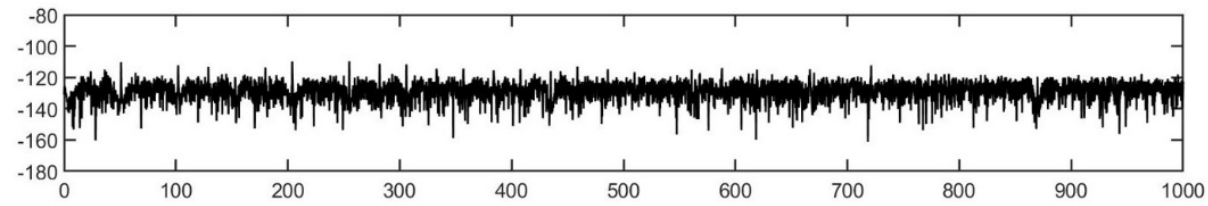

(c)

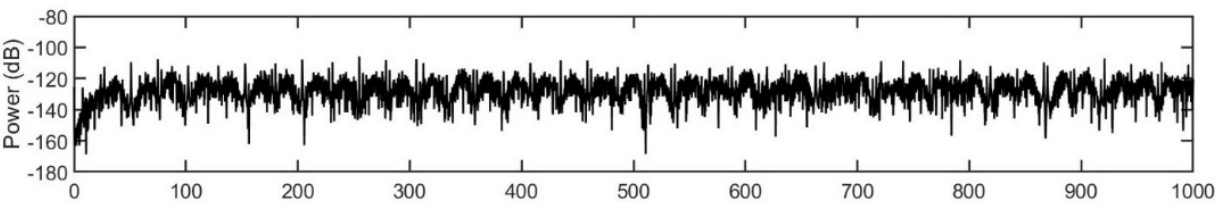

(d)

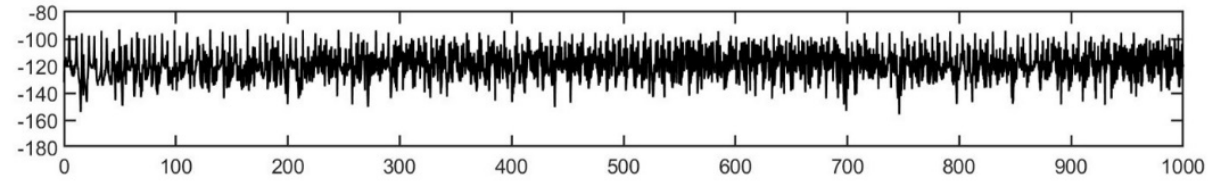

(e)

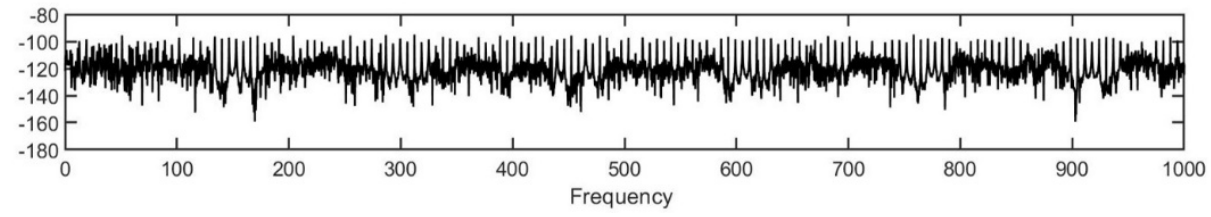

Fig. C2 Power spectrum of the signal after processed using linear prediction, (a) healthy planet bearing, (b) planet bearing with rolling element slippage, (c) planet bearing with inner race defect (d) planet bearing with outer race defect, (e) planet bearing with rolling element defect

Fig. C3 shows the power spectrums of the vibration signal after processed using the MED method and it is found that the power spectrum wave pattern is very similar with those in Fig. C2. This is to be expected as the MED method can only remove the transmission path effect and enhance the bearing fault jitter while it does not change the wave form. In Fig. C3(3), the impact from the bearing cage rotation can still be identified and the spacing of these frequency components is equal to the bearing cage frequency. 
(a)

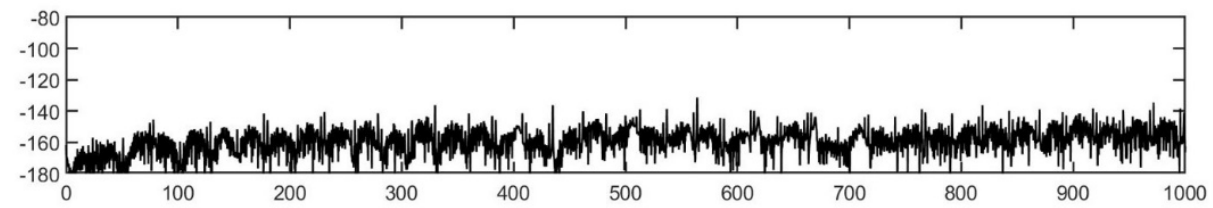

(b)

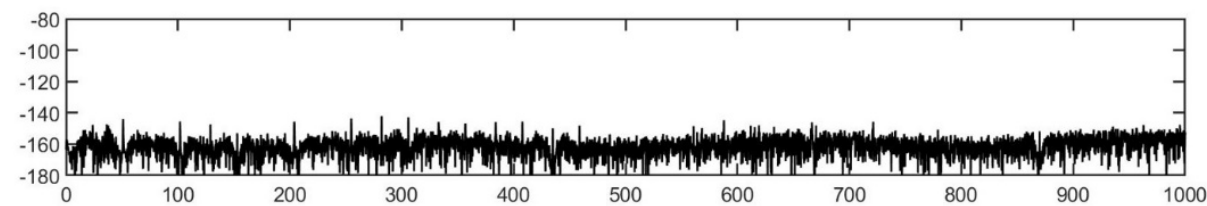

(c)

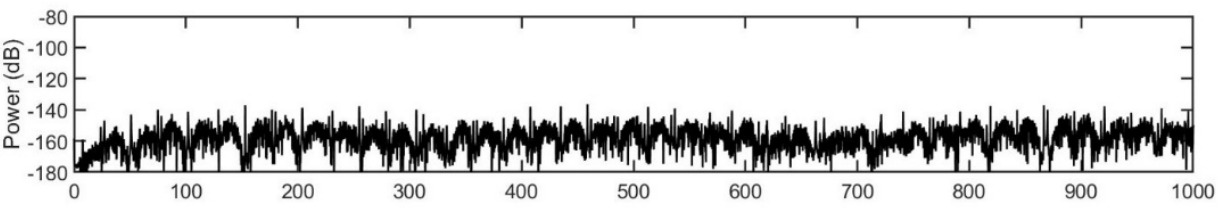

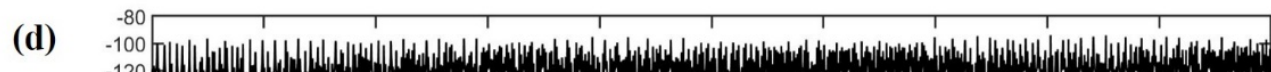

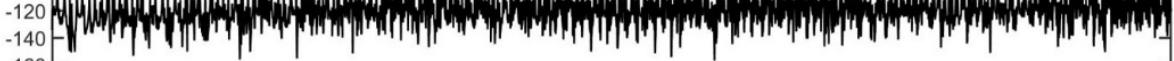

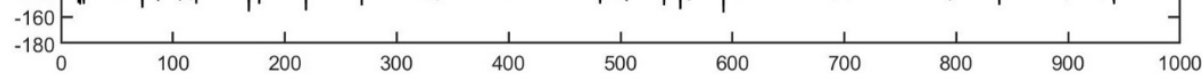

(e)

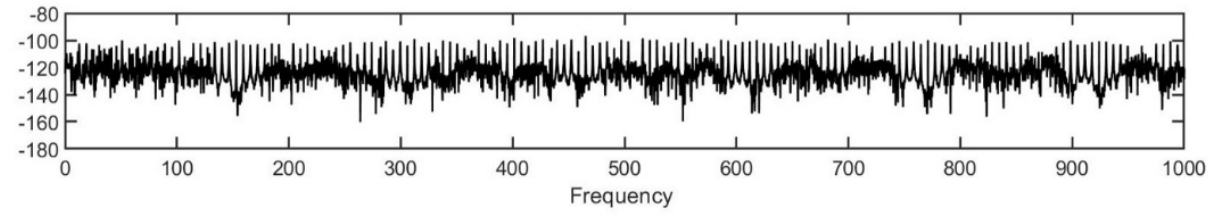

Fig. C3 Power spectrum of the signal after processed using MED, (a) healthy planet bearing, (b) planet bearing with rolling element slippage, (c) planet bearing with inner race defect (d) planet bearing with outer race defect, (e) planet bearing with rolling element defect 